University of Nebraska - Lincoln

DigitalCommons@University of Nebraska - Lincoln

Faculty Publications from the Harold W. Manter Laboratory of Parasitology

$9-1991$

\title{
Parasites and Sexual Selection: A Macroevolutionary Perspective
}

Deborah A. McLennan

University of Toronto

Daniel R. Brooks

University of Toronto,dnlbrooks@gmail.com

Follow this and additional works at: https://digitalcommons.unl.edu/parasitologyfacpubs

Part of the Parasitology Commons

McLennan, Deborah A. and Brooks, Daniel R., "Parasites and Sexual Selection: A Macroevolutionary Perspective" (1991). Faculty Publications from the Harold W. Manter Laboratory of Parasitology. 250. https://digitalcommons.unl.edu/parasitologyfacpubs/250

This Article is brought to you for free and open access by the Parasitology, Harold W. Manter Laboratory of at DigitalCommons@University of Nebraska - Lincoln. It has been accepted for inclusion in Faculty Publications from the Harold W. Manter Laboratory of Parasitology by an authorized administrator of DigitalCommons@University of Nebraska - Lincoln. 


\title{
The Quarterly Review of B IOLOGY
}

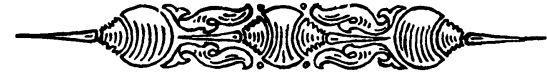

\author{
PARASITES AND SEXUAL SELECTION: \\ A MACROEVOLUTIONARY PERSPECTIVE
}

\author{
Deborah A. McLennan and Daniel R. Brooks \\ Department of Zoology, University of Toronto \\ Toronto, Ontario, Canada M5S $1 A 1$
}

\begin{abstract}
The Hamilton-Zuk hypothesis postulates a causal link between parasitism and the evolution of epigamic traits by intersexual selection. Oversimplified assumptions about basic parasite biology, ambiguous formulation of the hypothesis, and poor communication between ethologists and parasitologists have hampered its testing. The hypothesis is supported at the microevolutionary level if females show significant preference for lightly or uninfected males, if intensity of infection reflects host resistance to parasites that depress host fitness by causing disease, and if intensity of infection is related to the degree of epigamic development. It must be shown that particular parasites cause disease, that the host population is polymorphic for resistance to infection by those species, and that female hosts are capable of distinguishing male hosts with low parasite loads due to heritable aspects of host resistance from males that are uninfected due to chance. The macroevolutionary prediction of the hypothesis, that species displaying strongly developed epigamic characters should host "more parasites" than species with weakly developed epigamic traits, contradicts the microevolutionary dynamic of the hypothesis, and is too ambiguous. We propose a macroevolutionary prediction based on understanding the evolutionary origin of epigamic traits and the evolutionary origin of each host-parasite association. Associations originating in the ancestor in which the epigamic trait appeared corroborate the hypothesis most strongly; those originating prior to the evolution of the epigamic trait corroborate it weakly; those beginning after the origin of the epigamic trait could not have been involved in the origin and spread of the epigamic trait.
\end{abstract}

\section{INTRODUGTION}

$\mathrm{T}$ HE INFLUENCE of female choice on the evolution of male epigamic characters has been a controversial issue since Darwin first proposed his theory of intersexual selection (Darwin, 1871). Indeed, in a letter to Wallace, who had argued against the existence of female choice, Darwin concluded "we shall never convince each other" (Darwin and Seward, 1903; cited in Ruse, 1979: 209). Since that initial dispute, numerous researchers have demonstrated that intersexual selection is an important component in the mating system of a variety of species (see references in Bradbury and Andersson, 1987). After establishing the existence of such a mechanism, these researchers then turned their attention to the question of how that mechanism operated. Fisher (1930) proposed that the development of the male charac- 
ter and female preference for the character would "advance together" with ever increasing speed until the process was checked by "severe counterselection" against males bearing the exaggerated trait. At the very heart of the Fisherian hypothesis lies the assumption that the relationship between female choice and the preferred male character is arbitrary in terms of male viability. That is, females who choose males with bigger tails, brighter colors, or more vigorous displays get nothing out of the interaction other than the production of male offspring with the preferred character (see, e.g., O'Donald, 1962, 1967; Lande 1981; Kirkpatrick, 1982, 1986). The generality of the Fisherian process was challenged by proponents of the "good genes" school (e.g., Trivers, 1972; Zahavi, 1975, 1977; Borgia, 1979; Andersson, 1982, 1986; Nur and Hasson, 1983; Kodric-Brown and Brown, 1984) who argued that there is an association between expression of the epigamic character and male viability. Because of this association, females who choose mates with bigger tails, brighter colors, or more vigorous displays also get mates with "better genes," and thus produce offspring who possess the preferred character and are more vigorous than offspring of nonpreferred males. Unlike the Fisherian mechanism, then, the "good genes" hypothesis unites superiority in attracting mates and superiority in survival ability into a mutually reinforcing force of intersexual selection.

The chief objection to the good-genes hypothesis comes from population genetics. If female choice of genetically "superior" males is a strong enough directional force to influence the evolutionary elaboration of the character advertising this superiority, how could genetic variability, the materials of selection, be maintained in the population (Maynard Smith, 1978; Borgia, 1979; Taylor and Williams, 1982; Kirkpatrick, 1986)? Hamilton (1982) and Hamilton and Zuk (1982) attempted to answer this objection by exploring the relationship among parasite fitness, host fitness, and the degree of host sexual dimorphism (see also Freeland, 1976; Zuk, 1984). Their proposal, based upon studies of parasite population structure, rests upon three assumptions. First, parasites and their hosts are involved in a microevolutionary arms race. That is, the time lag between changes in characters involved in parasite of- fense and characters involved in host defense, produces cycles of coadaptation. This temporally varying selection pressure maintains a significant level of additive genetic variability for viability in the host population (Hamilton, 1982; Eshel and Aiken, 1983; Eshel and Hamilton, 1984; Anderson and May, 1985). Second, parasites adversely affect the health (viability) of their hosts. Third, the condition of male epigamic characters is an accurate and direct reflection of the bearer's health (a "revealing handicap," Maynard Smith, 1985). Consequently, the interaction between the oscillating force of natural selection on host viability and female choice for a male character that accurately communicates underlying viability results in a form of directional intersexual selection that does not exhaust genetic variability in the population (see also Tomlinson, 1988).

Kirkpatrick (1986) investigated the theoretical implications of the Hamilton-Zuk hypothesis by performing a series of 444 simulations based on 29 sets of parameter values, including viabilities of genotypes, selection coefficients, and recombination rates. He concluded that the mechanism, on its own, was not sufficient to guarantee the spread of alleles for the male character and female preference, particularly when both are rare in the population. He noted, however, that once these alleles, influenced by other evolutionary forces such as drift or selection on the pleiotropic effects of preference, had reached some threshold frequency, then the effects of the Hamilton-Zuk mechanism could cause both the preference and the male character to spread in a population. In other words, the interaction between hosts, parasites and the origin of female preference will not initiate the process of intersexual selection, but may reinforce that process once it has begun. Pomiankowski (1987a,b) reexamined the problem by incorporating more complex viability assumptions into his model. Using this new set of parameters, he was able to demonstrate that an exaggeration of the male character and the female mating preference could occur if the development of the epigamic trait was a direct revealer of viability. Although he disagreed with Kirkpatrick about the general importance of the Hamilton and Zuk mechanism, he also concluded that "The "handicap principle' by itself cannot initiate increases 
in female preference when the handicap is rare. It only works when a threshold value of female preference is exceeded, and Fisher's feedback process operates. . . . Both Zahavi's handicap and the revealing handicap act as one-way directional forces which, in concert with Fisher's feedback process, lead to the runaway exaggeration of male secondary sexual characters."

After uncovering a potential role for the Hamilton-Zuk mechanism on theoretical grounds, Kirkpatrick (1986) called for the resolution of questions surrounding the importance of such a mechanism in natural populations. Researchers have sought such a resolution on both a micro- and macroevolutionary level of analysis. Microevolutionary studies investigate the effects of parasite prevalence and intensity on the development of a male character and resultant female choice within one species of host. Results of such studies have been equivocal and attest to the difficulties involved in assessing the variables influencing parasite-host and male-female interactions (Table 1). Macroevolutionary studies focus upon comparisons of hosts across taxonomic levels. Hamilton and Zuk (1982) analysed 108 passerine species in their search for a positive correlation between number of blood parasites and degree of male host "showiness" (see Ward, 1988 for a similar study with freshwater fishes). Their discovery of a weak but significant association was at first corroborated by Read $(1987,1988)$ and later challenged by Read and Harvey (1989a,b) and Read and Weary (1990), who cautioned that data from related taxa are not independent, so persistent phylogenetic effects will confound statistical tests of the hypothesis. When the effects of phylogeny were controlled in the Hamilton-Zuk database, the strength of the correlation between parasite prevalence and male showiness was discovered to vary among different avian groups. Interestingly, this result mirrors the conclusions drawn by Kirkpatrick and the researchers working at the microevolutionary level: although the mechanism proposed by Hamilton and Zuk may not be generally applicable to all sexually selected systems, it may be important in specific cases. The importance, in turn, is dependent upon a variety of factors, including the life-history characteristics and population structure of the parasites in question, the biology of host resistance, the coevolutionary interactions between hosts and parasites, and the details of sexual selection (see also Endler and Lyles, 1989).

Although researchers disagree about the generality of this mechanism, they are united in their proclaimed interest in the "phylogenetic effects" revealed by Read (1987), Read and Harvey (1989a,b), and Read and Weary (1990) (see, e.g., Cox, 1989; Hamilton and Zuk, 1989; Zuk, 1989). We share in this enthusiasm, and in this paper we will show how the Hamilton-Zuk hypothesis can be examined from this phylogenetic perspective. Rather than attempting to identify and remove phylogenetic effects so they do not confound statistical analyses (e.g., Clutton-Brock and Harvey, 1984; Cheverud et al., 1985; Felsenstein, 1985; Pagel and Harvey, 1988; Gittleman, 1989; Gittleman and Kot, 1990), we will concentrate on the identification of these effects in order to incorporate them into the formulation of the Hamilton-Zuk hypothesis. We will begin with a discussion of the assumptions about parasite biology that underlie the hypothesis, and move from there to a macroevolutionary examination of the origin and interaction of host-parasite associations and epigamic characters. Ultimately, a fusion of both the microevolutionary and phylogenetic approaches, based on empirical input from parasitology and ethology, will be required to produce a more rigorous set of predictions, and from this a more robust theory of the relationship between parasitism and intersexual selection will be developed. We hope to demonstrate herein that there is enough overlap in these perspectives to initiate mutually beneficial crosscommunication.

\section{QUESTIONS ABOUT BASIC BIOLOGY}

The term "parasite" encompasses a variety of living organisms, running the gamut of diversity from viruses through bacteria to invertebrates and plants (Price, 1980). Like fish, parasites are not a monophyletic group, and hence cannot be diagnosed by the presence of characters shared by all members of the group. No ichthyologist, however, would ever equate a salmon morphologically, ecologically, physiologically, or behaviorally with a pipefish, nor would any biologist treat all fishes as interchangeable entities. Unfortunately, the recognition of species individuality accorded to most free-living organisms has rarely been given to 
TABLE 1

Results of microevolutionary studies investigating the relationships among parasite intensity, development of male character and female choice based upon that character*

\begin{tabular}{ll}
\hline System & \multicolumn{1}{c}{ Female choice } \\
\hline Field crickets/gregarines & $\begin{array}{l}\text { Preferentially attracted to } \\
\text { older males; older males are } \\
\text { (Zuk, 1987a,b; 1988) } \\
\text { less heavily parasitized than } \\
\text { younger males. }\end{array}$
\end{tabular}

Satin bowerbirds/feather lice (Borgia, 1986; Borgia and Collins, 1989)

\section{Guppies/nematodes} (Kennedy et al., 1987)

Fence lizards/malaria (Schall et al., 1982; Schall and Dearing, 1987; Schall and Sarni, 1987; Ressel and Schall, 1989)

\section{Three-spined stickleback/ciliate (Milinski and Bakker, 1990)}

Drosophila/nematodes (Jaenike, 1988)
Preferentially attracted to males with bowers; choose among bower holders based upon quality and decoration of bowers and there is a correlation between male dominance/ aggression and bower quality.

Females preferentially attracted to males based upon a variety of traits such as tail length, color and display frequency.

Not examined.

Preferentially attracted to more intensely colored (red) males.

Preferentially mate with unparasitized males.

Male-male interactions may also play a role.
Experimental results

No correlation between level of gregarine infection and number of females attracted however, there was a negative correlation between level of infection and spermatophore production that may influence a male's ability to successfully fertilize his mate.

Intensity of infection negatively correlated with male age. Bower holders had fewer parasites than nonbower holders; within the bower holders (the breeding population) there was a difference in intensity of infection, positively correlated with mating success in 1 of 3 years (in the other 2 years there was no difference among bower holders in either degree of infection or mating success based upon degree of infection). Intensity of infection had no effect on male condition, survivorship, bower quality or plumage brightness.

Among males matched for size, tail length and color, there is a strong negative correlation between intensity of infection and (1) male display rate and (2) the time a female spends responding to male courtship (one indicator of female choice).

Among males matched for size, and thus age, infected males displayed more ventral black coloration, spent less time engaged in social activity, and were more likely to be subordinate than uninfected males. The authors estimated that females using color as an indicator of malarial infection would only marginally improve their chance of choosing an uninfected male over random choice.

Parasitization caused a significant decrease in the intensity of a male's color signal and physical condition.

Not examined. Suggested that parasitism may reduce courtship vigor or color cues important in female choice of a mating partner.

* For additional studies see papers from the American Society of Zoologists' symposium on Parasites and Sexual Selection (Am. Zool., 30:225-352, 1990); this symposium was summarized by Pomiankowski, 1989.

parasites. The general perception of these creatures is that they are evolutionarily plastic, structurally degenerate carriers of disease. In the following section we hope to demonstrate that "parasite" does not equal "disease," that parasites are subject to, and constrained by, the same rules that govern the evolution of all biological systems, and that the biology of these diverse organisms is not only fascinating, but also is a crucial component to any study of the 
interaction between hosts, parasites and intersexual selection.

There are three aspects of parasite-host interactions that are of interest to students of sexual selection: the effects of parasites on the health of their hosts, host resistance, and parasite prevalence and intensity. Since parasitologists have been investigating these questions for many years, both the conceptual framework and the empirical database are well developed in each area. Rather than attempting to summarize the discoveries and advances over the past 50 years of parasitological research, we will present a brief outline of the current wisdom in each area and provide the interested reader with additional references. Given the complexity of these questions, however, we would like to reemphasize our belief that any investigation of sexual selection via parasite-host interactions requires the input of both ethologists and parasitologists.

\section{Do Parasites Affect the Health of Their Hosts?}

The question of whether parasites affect the health of their hosts has been widely debated among parasitologists. Until recently, most biologists accepted the intuitive theoretical perspective that the most evolutionarily successful parasite species were the least pathogenic. The reasoning behind this assumption is straightforward: parasites causing less severe damage to their host are at a selective advantage because they are able to reproduce for a longer period of time than their more pathogenic brethren. The benefits to the host of being infected by less pathogenic individuals are obvious. During the lengthy course of coevolution, then, the relationship between the host and its parasite should move toward a type of commensalism in which the "cost" of parasitism, although still present, is not unmanageable for the host (Schmidt and Roberts, 1985). Anderson and May (1982) questioned the simplistic assumption that interactions between parasite pathology and reproductive output always drive the host-parasite association down an evolutionary pathway toward minimal virulence. They concluded that "the coevolutionary trajectory followed by a particular hostparasite association will ultimately depend on the way the virulence and the production of transmission stages of the parasite are linked together: depending on the specifics of this link- age, the coevolutionary course can be towards essentially zero virulence, or to very high virulence, or to some intermediate grade."

What does the empirical evidence tell us about the effects of parasites on host health? There are a plethora of studies detailing the pathological effects of medically and veterinarily important parasites, in both the natural host and the laboratory-sculptured model host. Using these systems as evidence for the general pathology of parasites, however, is in effect a self-fulfilling prophecy, since only species that cause disease are intensely scrutinized. Nevertheless, the results of this research can provide us with information about the hostparasite relationship at the "virulent" end of Anderson and May's evolutionary scale; natural examples of highly lethal host-parasite examples do exist, albeit rarely, in nature (see, e.g., Crump and Pounds, 1985). Within this category, details of invasion and infection by the widespread, clinically important and tiny nematode Trichinella spiralis have been examined at length in both human beings and their laboratory equivalent, the ubiquitous white mouse.

The life cycle can be briefly described by following the life of one female juvenile worm: after being ingested by a suitable host (almost any mammal), she wanders in sinusoidal waves through the cells of the small intestinal floor feeding on host tissue (Wright et al., 1987), matures and reproduces in the intestinal epithelium, and produces about 1500 juveniles over 4 to 16 weeks. These juveniles work their way into the hepatic portal system, are carried throughout the host's body, feed on and encyst within skeletal muscle tissue, and are released when the infected host is eaten by another mammal. Although Homo sapiens is not a normal definitive host, invasion by the worm, a side effect of hunting (e.g., bears and seals) and association with domestic animals (e.g., pigs), has become an important medical problem. The effects of parasites on the mouse have been well documented on all levels of the host-parasite interaction. Genes have been identified that influence both the rate at which adult worms are expelled from the mouse's intestine and the fecundity of females (Dick et al., 1988). During the intestinal stage of the infection, oxygen consumption, body temperature (Kilgore et al., 1988), and food uptake from the intestine (Cas- 
tro and Olson, 1967; Castro et al., 1967) are all decreased relative to the levels of infection in the host. These physiological changes are mirrored in behavioral changes; during this period the activity of infected individuals decreases dramatically (Kilgore et al., 1988). Once the larvae have encysted in muscle tissue, the behavioral abnormalities become more pronounced (Zohar and Rau, 1986). Infected females are less likely to be courted by males, reject that courtship more often (Edwards and Barnard, 1987), and pay less attention to their young (Rau, 1985) than uninfected females. Pups born to and raised by infected mothers, although uninfected themselves, weigh less, are more hyperactive (Rau, 1985), and show a delay in development of reflexive, locomotor and memory processes (Nagy et al., 1983) relative to uninfected pups. This, in turn, may affect the future dominance status of males and the development of normal parental behavior in females. In addition, infected males are subordinate to uninfected males, and alpha males frequently lose their dominance ranking after becoming infected (Rau, 1983, 1984). There is thus a large body of evidence accumulating that supports the hypothesis that $T$. spiralis has a powerful adverse influence on the fitness of both infected individuals and their offspring (Rau, 1985; Zohar and Rau, 1986; for an excellent review of research in this area, see Ewald, 1983 and references therein).

Compared to the intense activity in the medical and veterinary fields, few studies have focused their attention upon the effects of parasites on their natural hosts, either in wild or in laboratory populations (Anderson, 1976; Bennett et al., 1976; Rand et al., 1983). Research in this area is bounded by several caveats because the effects of a given parasite species may vary with host age (Khan and Lee, 1989), host size (Loker et al., 1987), host sex (Evans et al., 1985), host stress level (Esch et al., 1975), and among closely related hosts (Cusack, 1986). The latter effect is particularly important because it emphasizes the dangers of generalizing from an association between host $A$ and parasite $A$ to an association between host $\mathrm{B}$ and parasite A. For example, Salmo gairdneri and $S$. trutta survived an association with the same Gyrodactylus sp. that killed Salvelinus fontinalis (Embody, 1924), while Salmo gairdneri fry were not affected by the infections of Gyrodac- tylus salmonis (Cone and Odense, 1984) that increased fry mortality significantly in Salvelinus fontinalis (Cusack and Cone, 1986). Additionally, experimental investigation frequently involves exposing individuals to levels of parasitism that are much higher than those documented in natural populations (parasites are generally overdispersed in the host population; Anderson and May, 1978). Since the effects of parasites on host health have rarely been rigorously examined in the field, it may be misleading to extrapolate from the extremities of the laboratory to the complexities of nature. Overall, the results of both laboratory and field investigations are equivocal. In some systems, parasite presence negatively affects some parameter of host fitness such as growth, longevity, or reproductive output [e.g., dipterans and water mites (Lanciani, 1986); tapeworms and oligochaetes (Courtney and Christensen, 1987)]. In other systems, the presence of the parasite has no detectable effect on the host [(e.g., rainbow trout and monogeneans $(\mathrm{Cu}-$ sack, 1986); tapeworms and oligochaetes (Calentine, 1967; Courtney and Christensen, 1987); hematozoans and birds (Fallis et al., 1974; Fallis and Desser, 1977)]. And in still other systems, the presence of the parasite may actually be beneficial to the host under certain conditions (see, e.g., Lincicome, 1971; Davies et al., 1980; Munger and Holmes, 1988). Let us investigate this question further by examining the effects of parasites on two sexually dimorphic species, the three-spined stickleback, Gasterosteus aculeatus, and the iguanid lizard, Anolis limifrons.

Three-spined sticklebacks, Gasterosteus aculeatus, find copepods to be attractive food items. Unfortunately, since these crustaceans are the first intermediate host in the life cycle of the avian tapeworm Schistocephalus solidus, this dining preference exposes the diners to infection. Once eaten, the larval tapeworm migrates into the skeletal muscles, and develops and grows into a large juvenile, forestalling sexual maturation until released in its definitive avian host (usually a heron). In this system, the stickleback is simply a handy, transitory vehicle for the parasite to move from its birth in the water to its home in the bird, so it is not surprising that the relationship between the fish and the parasite is a pathological one. Infected individuals, easily recognized by their extremely bloated abdomens, are physiologically com- 
promised, slower swimmers, less successful foragers, and reproduce at a reduced rate (Arme and Owen, 1967; Pennycuick, 1971; Milinski, 1984; but see McPhail and Peacock, 1983). More importantly, from the tapeworm's perspective, these individuals are willing to take more risks during foraging, and demonstrate an increased oxygen requirement that drives them to the water's surface, gasping at the airwater interface (Lester, 1971). Both of these behavioral changes increase the likelihood that the vehicle will be eaten by a heron, transporting the parasite to its definitive host, where it matures and resides in relative harmony for a short time. The coevolutionary associations between the parasite and its intermediate host are under strong selection pressure because the evolutionary stakes are higher at this stage of the life cycle. If the parasite does not reach its definitive host, it cannot reproduce, so the effects of nontransmission are absolute on parasite fitness. From the host's perspective, infection reduces reproductive output and longevity, but since the amount of this reduction depends upon factors such as age of infection, intensity of infection and intensity of predation, the effects on host fitness are relative, not absolute. All other things being equal, then, the association should coevolve toward a balance at the high end of Anderson and May's virulence scale (see Dobson, 1988 for an extensive investigation of the consequences of behavior manipulation by parasites on the population dynamics of their hosts; see also Holmes and Bethel, 1972; Minchella, 1985; Moore and Lasswell, 1986; Quinn et al., 1987 for excellent discussions). In this particular system we have evidence that the parasite is affecting the health of its host; however, because the interaction is so strongly biased in favor of the parasite, it is difficult to detect variation in male response to that parasite. This, like many associations between parasites and their intermediate hosts, therefore appears to be an unsuitable system for investigations of the relationship between parasites, hosts, and sexual selection.

Infection with Plasmodium balli and members of the $P$. tropiduri species group in Anolis limifrons follows the usual malarial course: parasites injected into the bloodstream of a suitable lizard host eventually enter red blood cells, where some individuals undergo cycles of intense asexual reproduction, bursting out of the old and infecting new RBCs, and other individuals form gametocytes that remain quiescent until ingested by the invertebrate host, in which fertilization and embryogenesis occur (see Rand et al., 1983 for a description). Like the relationship between the tapeworm, stickleback and heron, the parasite must be transmitted to a second host species to complete its life cycle. The dynamics of transmission, however, are different from the preceding example because the lizard need only be located and bitten, not consumed, by that host (reducing selection pressure on the lizard to avoid the parasite), and the parasite multiplies asexually within the lizard, thus increasing the probability of transmission (reducing the selection pressure for profound host behavioral alterations by the parasite). All other things being equal, then, we would predict that this association should coevolve toward a balance at the lower end of Anderson and May's virulence scale. Rand et al. (1983) investigated the hypothesis by collecting 1,287 blood smears from 735 Panamanian anoles over a two-year period. This extensive study revealed that neither the presence nor intensity of malarial infection affected lizard weight, food intake, time of activity, female reproductive condition (measured as appearance of oogenesis, number and size of eggs), growth, survivorship, or predation. The authors cautioned that the effects of infection may be felt more strongly early in lizard development, but once an individual has reached maturity "malaria does not have a marked effect on the anoles that it infects." In this particular system, we have evidence that the parasite is not affecting the health of its adult host, so all reproductively active males are projecting the same message: "I made it through the juvenile bottleneck." Since males who did not make it through the bottleneck are not a part of the breeding population, the message is of limited value to a "choosy" female. Additionally, there are at least two types of reproductively active males in this population - those who were infected as juveniles and survived the infection, and those who have never been exposed to the parasite, and may or may not have survived, so the message is an ambiguous one in terms of overall male "vigor." So, like the stickleback example but for different reasons, this would not be a suitable system for investigating the relationship between 
parasites and sexual selection.

The current database provides us with an important insight into host-parasite associations: never assume a priori that the parasite is adversely affecting the health of its host. The host-parasite association can travel down a number of evolutionary pathways toward reduced or increased pathogenicity, and this, in turn, will affect the suitability of the association for studies concerned with documenting the interaction between host, parasites and female choice among reproductively active males (Table 2).

\section{What Is Involved in the Evolution of Host "Resistance" to Parasites?}

The interaction between a parasite and its host has traditionally been viewed as a constant struggle between the parasite's attempt to invade the host and the host's attempt to evade the invader (Mode, 1958; Ehrlich and Raven, 1964; Feeny, 1976; Dawkins and Krebs, 1979).
There are two predicted outcomes of this biological "arms race." Either the host is resistant and effectively parries the invading parasite, or the host is susceptible and the parasite becomes established in its new home. According to this perspective there are two host phenotypes, "susceptible" and "resistant," and two parasite phenotypes, "virulent" and "benign," the development of which is influenced by genetical and physiological factors. Hamilton (1982) and Hamilton and Zuk (1982) used this concept of coadaptive cycling between hosts and parasites as the foundation for their theory. Although this traditional perspective of host resistance was retained by biologists outside of parasitology, it was being challenged within that discipline prior to Hamilton and Zuk's proposal. Price (1980) outlined the emerging new viewpoint thus: "The selection pressure exerted by highly specialized organisms on host populations can produce the most unexpected results. We are not yet sensitive enough to appreciate even a

TABLE 2

Summary of the associations between the strength of a parasite's adverse effect on its host's health, and the suitability of the system for a sexual selection investigation*

This simplistic analysis is based upon the assumption that all males are equally exposed to parasites. As discussed previously, the reliability of the message conveyed in the degree of epigamic development will be decreased if all males are not equally exposed to parasitic invasion.

Strength of adverse effect on host health

1. No effect on adults or juveniles

2. Strong effect on juveniles - no effect on adults

3. Moderate effect on juveniles - no effect on adults

4. No effect on juveniles-moderate effect on adults

5. Strong effect on adults
Suitability for sexual selection study

Unsuitable

Unsuitable: only "resistant" males make it through the juvenile bottleneck; however, once mature, there is no difference among breeding males based on the early host-parasite association.

Suitable: if effects of parasitism during development are translated into differences between breeding males, this provides "truthful" information about those males.

Suitable: if the effects of parasitism in the adult are translated into intermale differences in the degree of epigamic development, there is potential for a female to use this information as an indicator of male "vigor."

Unsuitable: pathogenicity is too high, infected individuals so physiologically or behaviorally disrupted that they are effectively removed from the breeding population and are thus not part of a female's choice based upon differences among reproductively active males.

\footnotetext{
* See also Hamilton and Zuk, 1982; Endler and Lyles, 1989.
} 
small fraction of them. ..." The resurgence of interest in using parasites as model systems for studying the evolution of biological associations has prompted many authors to reexamine the problem of host resistance. These studies have indicated that, contrary to the traditional perspective, there may be numerous evolutionary outcomes to the struggle between hosts and parasites. For example, research in a variety of systems has uncovered intraspecific genetic variability in both parasite infectivity (see, e.g., Dick, 1983; LoVerde et al., 1985; Tanuri et al., 1985; Collins et al., 1987; Nadler and Honigberg, 1988) and host susceptibility (see, e.g., Richards, 1975, 1976; Wakelin, 1978; Sitepu et al., 1986; Wassom et al., 1986; Mulvey et al., 1987; Leighton et al., 1989). Additionally, the development of an immune response may be dependent upon a complex polygenic interaction (e.g., between a variety of "resistancepromoting" and "disease-promoting" cells: Moll and Mitchell, 1988), and resistance may be transferred from a mother to her offspring, at least in mammals (Knopf and Coghlan, 1989). And finally, the old parasitological maxim that the prevalence and intensity of infection within a host population represents the end point of an interaction between the genetical, physiological, behavioral, and ecological characteristics of both the host and the parasite, is gaining increasing importance in studies of host resistance. As we will discuss in the next section, host infection may vary with age, sex, size, and season, so assessments of the relationship between number of parasites and the degree of male character development cannot be conducted in the absence of this information. This caveat is not new to biology. No ethologist would include sexually immature individuals in an analysis of courtship behavior. Overall, then, as suggested by Price, these studies have demonstrated that the relationship between offensive parasite and recalcitrant host is far more complex than previously thought (for a gametheoretical discussion of this problem see Cohen and Newman, 1989).

Minchella (1985) suggested that a variety of alternative strategies, based upon changes in resistance and changes in life-history tactics, are available to hosts faced with invading parasites. He extended the classical argument for the evolution of host resistance by arguing that if parasite infection is causing a decrease in host fitness, there should be strong selection for any change that counters this decrease if the cost of host resistance is less than the cost of being infected. Minchella proposed that these alternative strategies in the evolution of host resistance depended upon the interaction among four factors: intraspecific variability in host resistance at the genetic level, the strength of directional selection against susceptibility as measured by the effect of the parasite on host fitness, the probability of host infection by the parasite (roughly equivalent to the prevalence of the parasite in the host population), and the cost of resistance, stemming from possible compensatory changes associated with increasing resistance such as disadvantageous changes in fecundity (Wright, 1971) or an increase in the energy input required to combat the invader.

The cost of resistance also depends upon whether the host is simply biochemically unsuitable for parasite development (passive resistance) or whether the host reacts to the parasite's presence (active resistance). Theoretically, active resistance, which involves the physiological chain reaction "recognize invader, immobilize invader and destroy invader," should be a more costly strategy and thus more difficult to evolve, than passive resistance. Interestingly, this prediction has been confirmed for one of the most intensely studied parasitological systems to date; the relationship between the parasitic flatworm Schistosoma mansoni, the perpetrator of human schistosomiasis or Bilharzia disease, and its intermediate snail host Biomphalaria glabrata (see discussion and references in Minchella, 1985; for additional discussions see Rollinson and Southgate, 1985; Richards and Shade, 1987). Since the host's "strategy" for dealing with parasite invaders is determined by the outcome of the interactions among the preceding four factors, Minchella argued that the evolution of host resistance will occur only if the probability of infection multiplied by the cost of being infected is greater than the cost of host resistance.

If the cost of host resistance is high, and the probability of being infected is low and unpredictable, Minchella proposed that the hosts and parasites might travel down an alternate evolutionary pathway involving changes in lifehistory variables. Although there are numerous examples of parasites affecting the behavior of their hosts (see references in Minchella, 
1985), the evolution of host counteradaptions has rarely been studied beyond the level of physiological resistance. Some tantalizing glimpses into host-parasite interactions are available, however, once again, from studies of Biomphalaria glabrata. Four to six weeks after infection by Schistosoma mansoni miracidia (the first larval stage), the snail's reproductive output begins to decrease, and eventually most of the infected individuals are physiologically castrated. This example leaves no doubt about the negative effects a parasite can have on host fitness. Now, we already know that the evolution of active resistance to these larval invaders has not evolved very often, if at all, in these snails. Are the parasites winning the arms race in this system? In order to answer this question, researchers focused their attention on the host's behavior during the interval between penetration by the miracidia and the beginning of reproductive interference. These studies revealed a fascinating response, now termed "fecundity compensation." Immediately following penetration, the host embarks upon a spurt of egg laying, continuing along this intensified pathway until the physiological impact of the parasite's presence begins to affect its reproductive output. Overall, this increase is hypothesized to compensate, at least to some degree, for expected future reproductive losses (see also Crews and Esch, 1986 for a similar discussion of a different host-parasite system).

The preceding discussion, although brief, has shown that the evolutionary interaction between parasite infectivity and host resistance is more intricate than previously thought. There are a number of evolutionary pathways available to host-parasite associations, and the direction taken depends upon the interplay between the ecological and genetical constraints and flexibilities inherent to each individual system. If this single-species interaction is magnified by the actual number of different parasite species associated with any given host, the problem of "host resistance" takes on almost overwhelming complexity. Such complexity does not invalidate Hamilton and Zuk's original concept about a selective interplay between parasites, hosts, and female choice; it does, however, call into question the specific mechanism proposed to explain how this interplay might occur. Kirkpatrick (1986) concluded that the interaction between the oscillating nature of host-parasite associations and the directional nature of female choice was not sufficient to explain the evolutionary elaboration of the male character and did not increase population fitness. Overall, then, theoretical information from population genetics and empirical data from host-parasite studies are consonant in their conclusion that a refinement of the mechanism is required. Does this condemn field biologists to inactivity within a modelless limbo until the next theoretical advance occurs in this area? Of course, the answer to this question is "no, with some caveats." In the best of all possible worlds, there would be a profusion of host-parasite systems for which the details of resistance and infectivity had been examined on genetical, physiological, ecological, and behavioral levels. In the real world, most parasitologists have focused their attention upon controlled, laboratory investigations of medically and veterinarily important parasite species. Therefore, it becomes even more critical that a parasitologist is included in any parasites-andsexual-selection project, maximally to investigate the host-parasite association, minimally to provide best guesses based upon knowledge of the parasite species in particular, and the dynamics of parasite-host interactions in general. Although it is not perfect, this strategy is still preferable to one that proceeds from a preferred host type to an associated parasite, chosen at random or because it is easy to count, to consultation of papers concerning the general biology of the chosen parasite.

\section{Factors Affecting Parasite Prevalence}

To ciari..y first a point of terminological confusion, note that the terms prevalence, incidence and intensity are used by parasitologists to describe the distribution of one species of parasite within a host population (for definitions see Margolis et al., 1982). It is important to remember that, unless otherwise stated, the word "parasites" refers to conspecifics, not an amalgam of every parasite species found in the host. While keeping this in mind, let us return to the problem of parasite prevalence. The Hamilton-Zuk hypothesis requires that resistant males court more vigorously, develop brighter colors, or longer tails, and thus truthfully advertise their "genetic superiority" to their nonresistant, parasite-stressed conspecifics. In order to postulate that the dynamical interac- 
tion among parasite load, male quality and female choice produces a strong enough selective force to affect the evolution of the male epigamic trait, we must also assume that all males are equaily exposed to parasite infection. Is this assumption valid? Parasite population structure is generaily overcispersed or contagious śsee, e.g., Ancierson and May, 1978; Price, 1980; Anderson, 1982; Esch, 1983; Dobson, 1988; Yanez and Canaris, 1988), meaning that there is a very high variance to mean ratio when abundance or relative density (number of parasites per host) is documented. From the parasite's point of view, this allows the host population to carry a larger total number of parasites for any given prevalence (percent of hosts actually infected with at least one parasite) than would be possible if infection followed a Poisson distribution. Typically, more than 50 percent of the parasites occur in less than 5 percent of the hosts; hence, there are relatively few heavily infected organisms in the host population at any given time. It has been tempting to explain these heavily infected hosts as being evolutionarily unfit for some reason, and assume that their heavy parasite load indicates strong selection against them.

Anderson and May (1979) examined this assumption for one system, larval schistosomes and their molluscan intermediate host, and concluded that the extant population models were poor precictors of many aspects of the association because the biological assumptions were unrealistically simplified. They emphasized that, outside of the laboratory, parasites and their hosts do not inhabit a spatially and temporally uniform world. For example, parasite distribution patterns are determined, in part, by the probability of host contact with infective stages of the parasite. Depending upon the system, this probability will be influenced by host interactions (direct transmission from host to host), the availability and population dynamics of intermediate hosts, and the distribution of infective stages (e.g., Riggs and Esch, 1987). If, as more studies are revealing, this distribution is clumped in the environment, then the probability of any host individual being iniected is strongly subject to its chance contact with a clump of infective parasite stages (Anderson and Gordon, 1982). An overdispersed population structure is thus expected on purely stochastic grounds (Ander- son, 1982; Dobson, 1988), weakening the assumption that differential distribution of parasites within a host species reflects differences in resistance to infection among equally exposed individuals. The assumption is further weakened by the observation that host age (Smith et al., 1985; Loker et al., 1987; Courtney and Christensen, 1988), host sex (Whitlock, 1937; Pickering and Christie, 1980; Smith et al., 1985; Lanciani, 1988), host social structure (Freeland, 1979; Moore et al., 1988; Blower and Roughgarden, 1989), and changes in environmental factors such as season, temperature and water level either singly, or in combination, can influence parasite prevalence and intensity in a host population (see, e.g., Crews and Esch, 1986; Gleason, 1987; Marcogliese and Esch, 1989; for two excellent longterm studies of the influences of environmental factors on parasite population dynamics, see Janovy and Hardin, 1988, and Riggs and Esch, 1987 and references therein).

Overall, the general observation that there is a high variability in prevalence and intensity of infection both among hosts and within an individual host over time can be attributed to the interaction of a variety of factors, only one of which need be heterogeneity in host resistance (Anderson and May, 1979; Anderson, 1982; Anderson and Gordon, 1982; Scott and Gibbs, 1986; Wallace and Pence, 1986; Moore et al., 1987). Hence, the assumption that all host individuals have been equally exposed to parasitism is unfounded, introducing an element of chance into an intersexual communicative interchange based upon degree of parasitism. Without information about the factors affecting parasite distribution on the host of interest, we cannot assume that the absence or low numbers of a parasite is an accurate reflection of an individual host's resistance. Heavily infected hosts may be either unfit or unlucky, an uninfected host may be either resistant or lucky. Consequently, if host health is adversely affected by increasing parasite load, then a female will be exposed to, minimally, four male "health messages": males with high parasite burdens (nonresistant), truthfully advertising their poor health; males with high parasite burden (resistant or nonresistant and unlucky), ambiguously advertising their "genetic quality"; males with no or low parasite burdens who have been exposed to parasitism (resistant), 
truthfully advertising their good health and "good genes"; and males with no or low parasite burdens who have not been exposed to parasitism (resistant or nonresistant and lucky), ambiguously advertising their "genetic quality." Depending upon the frequency of female exposure to the second and, more importantly, the fourth male message, the presence of ambiguous information about the mating system will weaken the directional association between male character development, degree of parasitism, and female choice.

Although it is subject to the caveats discussed above, the microevolutionary prediction of the Hamilton-Zuk hypothesis is straightforward: within a species, females should prefer males with fewer parasites. The macroevolutionary prediction, on the other hand, is more obscurely worded, "animals that show more strongly developed epigamic characters should be subject to a wider variety of parasites" (Hamilton and Zuk, 1982, p. 385, our italics). Confirmation of this prediction is provided by uncovering a strong correlation between some measure of parasite load and the degree of epigamic development across host taxa. When searching for this correlation, however, parasite species are often combined to produce one "infestation" value regardless of the differences in pathology that may be caused by different species of parasites, and prevalence, incidence and intensity data are used interchangeably with each other and with more nebulous terms applied to the distribution of more than one parasite species (parasite load or burden). Therefore, it is initially unclear whether Hamilton and Zuk's prediction of a "wider variety" of parasites refers to more parasites absolutely, or to more species of parasites. Authors have criticized the first interpretation, arguing that the model could also make the opposite prediction: "species with bright males should be the least parasitized if female selection for male brightness has lowered the level of infection in the population" (Borgia, 1986, our italics) and "if however, parasite load is reduced as a consequence of female choice for resistant mates, showiness might become negatively correlated with parasite load" (Read and Harvey, 1989b, our italics). So, this leaves us with the second interpretation: sexually showy species should host more species of parasites than their less flamboyant relatives. Let us investigate this prediction in more detail.

The Hamilton-Zuk hypothesis was originally formulated to explain the evolution of epigamic characters, not to explain the macroevolutionary distribution patterns of parasites among their hosts. Incorporation of these distribution patterns into our picture of host and parasite interplay and sexual selection, however, uncovers two important weaknesses in the macroevolutionary prediction as it is currently stated. The first problem is a methodological one. If we uncover a correlation between the number of parasite species inhabiting a host and degree of epigamic development in the host, we cannot accept that correlation as evidence of causality without determining that the factors involved in the observed asymmetrical distribution of parasite species could not, in turn, be involved in the evolution of the sexually selected character (Harvey and Partridge, 1982). For example, based upon a correlation between parasite load and the degree of male showiness in passerine birds, Hamilton and Zuk concluded that the evolution of showiness was being driven by the interaction between a host-parasite arms race and female choice for a male character that accurately reflected the outcome of that race. Although this is one possible explanation for the observed correlation, it is not the only one. Kirkpatrick and Suthers (1988) examined blood smears from 59 species of North American passerines in an attempt, among other things, to uncover the intrinsic and extrinsic factors associated with increased or decreased risk of infection by members of the parasite genera Haemoproteus, Plasmodium and Leucocytozoon. They discovered that passerine species with ground feeding habits were significantly more likely to be infected with blood parasites in general, and Leucocytozoon spp. in particular, than passerine species feeding above the ground. Bennett et al. (1978) and Kirkpatrick and Smith (1988) reported that the prevalence of blood parasites in colonially nesting birds was significantly higher than in noncolonial nesters. And finally, various authors have suggested that susceptibility to infection by insect-borne blood parasites may be influenced by the height of the nest location preferred by a given avian species (Greiner et al., 1975; but see Kirkpatrick and Suthers, 1988). So, in this system, the number of parasite species associated with a host is strongly 
correlated with foraging, nesting and social habits of the birds, any one of which might, in turn, be associated with the evolution of sexual dimorphism. If this is the case, then the observed correlation between parasite load and sexual dimorphism is an artifact of the causal interaction between ecological factor $z$ and parasite load and ecological factor $z$ and sexual dimorphism (see also Read, 1987; Scott and Clutton-Brock, 1989).

The second problem is more fundamental and it is inherent in the structure of the macroevolutionary prediction as it is currently formulated. From the observation that parasite species are not equally distributed among host species, Hamilton and Zuk extrapolated the conclusion that some hosts were more susceptible to parasite attack than others. Equating "susceptible" with "less capable of fending off parasitic invasion," however, returns us to the resistance paradox: within a species, preferred males are more resistant to parasitism than nonpreferred males, but species containing these preferred individuals are less resistant to parasitism than species without this type of choice dynamic. Once again, the results of parasitological research can help us resolve this problem, not by revealing some magical answer but by demonstrating that the paradox does not really exist. Macroevolutionary patterns of parasite distribution are determined by a complex interaction among a variety of factors, only one of which may be changes in species-specific host "resistance." For example, the distribution of helminth parasites in frogs is determined, in part, by both parasite biology and host biology. The infective stages of the majority of helminth species are generally transmitted to the primary host in the water, and as adults, some anurans (e.g., toads and their relatives) are terrestrial or fossorial, while other anurans (e.g., leopard frogs, green frogs, bullfrogs) are aquatic. Because of the constraints imposed by the biology of the hosts and parasites, we would expect the aquatic ranids to host more helminths than terrestrial bufonids. Not surprisingly, studies by parasitologists have all shown a strong positive relationship between the number of parasitic helminths infecting anurans and the aquatic habits of the anurans (Brandt, 1936; Prokopic and Krivanec, 1975; Brooks, 1976). In this system, then, there will be a differential distribution of parasite species regardless of the "susceptibility" of the hosts. Because the distribution of parasites among potential host species is more complex than just an extrapolation of population-level host resistance, there is no a priori reason to believe that a sexually showy species will always be associated with more parasite species than its less flamboyant relative.

We can approach this problem from another direction by restating the Hamilton-Zuk prediction in the following manner. The existence of female choice in species A does not cause species $\mathrm{A}$ to have more parasites than species B; however, the fact that species A has more parasites than species B may cause the evolution of epigamic characters via female choice in species A. Now, consider a hypothetical group of birds comprised of two sister groups, the ABCidae and DEFidae (Fig. 1). All the members of the ABCidae are sexually monomorphic and host five species of parasites. All the members of the DEFidae are sexually dimorphic and also host five species of parasites. Experimental investigations have demonstrated that females in the DEFidae prefer males with brighter feathers, and these males, in turn, have lower numbers of parasites than their nonpreferred conspecifics. The microevolutionary study confirms that a Hamilton-Zuk mechanism is operating in the DEFidae. The macroevolutionary analysis, however, does not confirm this result because it contradicts the predicted relationship between the degree of sexual showiness and the number of parasite species. Is there a way out of this conflict?

Let us return to our initial formulation of the macroevolutionary prediction and refine

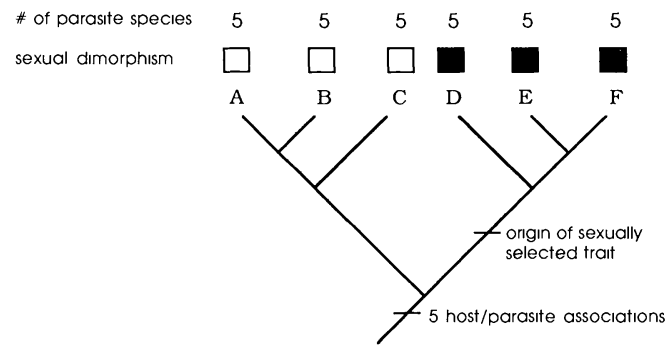

Fig. 1. Distribution of Parasites and Sexual Dimorphism Among a Clade of Hypothetical Birds

White boxes, sexual dimorphism absent; black boxes, sexual dimorphism present. 
it. The existence of female choice in species A does not cause species A to have more parasites than species B; however, the fact that species A has more parasites than species B may cause the evolution of epigamic characters via female choice in species A once that trait appears in the population. The presence of parasites does not cause the sexually selected trait to appear in the population. If it did, evolution would be Lamarckian, not Darwinian. Depending upon the details of the genetical-developmental system of the host, once the trait has appeared, the presence of parasites may influence its evolutionary success and elaboration. Given this time lag, there is no reason to believe that a relationship should exist between the number of parasite species and the degree of epigamic development. In the preceding example, the presence of an ancestral host-parasite association was sufficient to promote the spread of an epigamic character when it appeared (Fig. 1). We can also make a case for sexually dimorphic species hosting fewer parasites than their monomorphic relatives of the interaction. For example, the interaction between the dimorphic species and their parasites may be a more pathological one. On the other hand, as depicted in Figure 2, the monomorphic hosts may have continued to pick up parasite species, while the dimorphic hosts remained associated with parasites that had been originally involved in the host-parasite sexual selection dynamic. A case for sexually selected species having more parasites than their relatives in

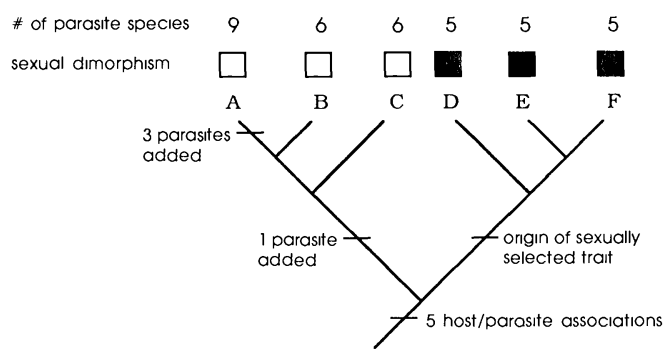

Fig. 2. Association between Sexual Dimorphism AND NUMBER of Parasites

In this scenario, members of the ABCidae have continued to pick up parasites, while members of the DEFidae have retained the ancestral host-parasite associations. some systems can also be made. Overall, then, the Hamilton-Zuk hypothesis does not make a prediction about the relationship between the number of parasite species and the degree of epigamic development in the hosts, aside from the trivial prediction that at some time in their history the dimorphic species must have been associated with parasites. It is important to emphasize here that this does not invalidate the hypothesis; it only forces us to rethink the macroevolutionary prediction. This suggests that the macroevolutionary outcome of the Hamilton-Zuk mechanism is qualitatively different from, rather than being an extrapolation of, the microevolutionary dynamic based upon parasite numbers. We will now examine this question further, and present what we believe to be a more robust macroevolutionary prediction for the Hamilton-Zuk hypothesis.

\section{QUESTIONS ABCUT EVOLUTIONARY ORIGINS}

The Hamilton-Zuk hypothesis is concerned with uncovering correlations between the extent of male epigamic development and parasite prevalence. This, in turn, is an extension of the general adaptationist program, in which observations of correlations among traits in extant species are used as the basis for hypotheses concerning the evolutionary relationship between the traits. There are, however, three components to character evolution: origin, diversification and maintenance. Microevolutionary studies concentrate on the maintenance of traits in current environments where the processes shaping the interactions between the organism and its environment can be observed and measured directly. After untangling this complicated web, these researchers then extrapolate backwards to the processes involved in the character's initial appearance in, and subsequent spread through, the ancestral species.

A macroevolutionary analysis complements these studies by providing direct estimates of phylogeny that can be used as a template for reconstructing the historical patterns of character origin and diversification. Such a template can help biologists to focus their search for the processes underlying these evolutionary patterns. For example, consider an interesting (but improbable) group of species with the following characteristics (Table 3) and phylogenetic relationships (Fig. 3). In this group, the rela- 
TABLE 3

Distribution of three characters among four members of a monophyletic group (species $\mathrm{A}+\mathrm{B}+\mathrm{C}+\mathrm{D}$ ) and the outgroup (taxon $\mathrm{X}$ )

\begin{tabular}{llllll}
\hline & \multicolumn{5}{c}{ Species } \\
\cline { 2 - 6 } Trait & \multicolumn{1}{c}{$\mathrm{X}$} & $\mathrm{A}$ & \multicolumn{1}{c}{$\mathrm{B}$} & \multicolumn{1}{c}{$\mathrm{C}$} & $\mathrm{D}$ \\
\hline Color & blue & blue & red & red & red \\
Shape & square & square & square & round & round \\
Size & small & small & small & small & big \\
\hline
\end{tabular}

tionship between a character and the environment in which it originated can be investigated for only one taxon and one character state, namely, the evolutionary increase in size ("big") in species D. Researchers who are interested in the processes involved in character origin and adaptive success, if any, should concentrate their efforts on this species. The presence of small, blue and square characters in species A; small, red and square characters in species $B$; small, red and round characters in species $\mathrm{C}$; and red and round characters in species $D$ are all ancestral legacies. Studies of these species will uncover the processes involved in character maintenance. By combining the results from all these studies we will be provided with a more direct estimate of the relationship among the processes underlying the origin, spread and maintenance of potentially adaptive traits. The incorporation of both the patterns of the past and the processes of the present into our framework of evolutionary explanations will thus strengthen our hypotheses of evolutionary change and interactions.

In the following section, we will discuss methods for uncovering the origin of the epigamic character and the origin of the association between, and coevolutionary interactions among, hosts and their parasites. It is not our intention to present an in-depth discussion of the assumptions, strengths and weaknesses of the methods. We hope only to demonstrate that, once unveiled, the macroevolutionary patterns can provide important information about evolutionary processes. In order to fully appreciate the relationship between pattern and process, however, it is important to understand the fundamental mechanics of the various phylogenetic methods. Therefore, we will introduce each section with a brief, step-by-step discussion of a very simple and unambiguous example.

\section{The Origin of the Sexually Selected Character in the Host Group}

One cardinal rule in a phylogenetic analysis is that one should never bias an analysis by using the ecological information about to be studied to build a phylogenetic tree. Ethologists who are interested in determining the origin of a sexually selected trait must therefore begin their explorations with two pieces of information: a phylogenetic tree for the group and information about the development of the epigamic character throughout the group. The best supported (most parsimonious) sequences of evolutionary transformations for the epigamic character, either binary or multistate, can then be determined with reference to the phylogenetic tree. This method, called character optimization (Farris, 1970), is best illustrated by data from the Drosophila of ethology, stickleback fishes.

Within the family Gasterosteidae, the threespined stickleback has been extensively studied from almost every morphological, ecological and behavioral angle because of one biological attribute. In the spring males undergo a wondrous transformation from inconspicuous silver green fishes to flamboyant mosaics of flame scarlet bodies and flashing aquamarine blue eyes. When the relatives of Gasterosteus

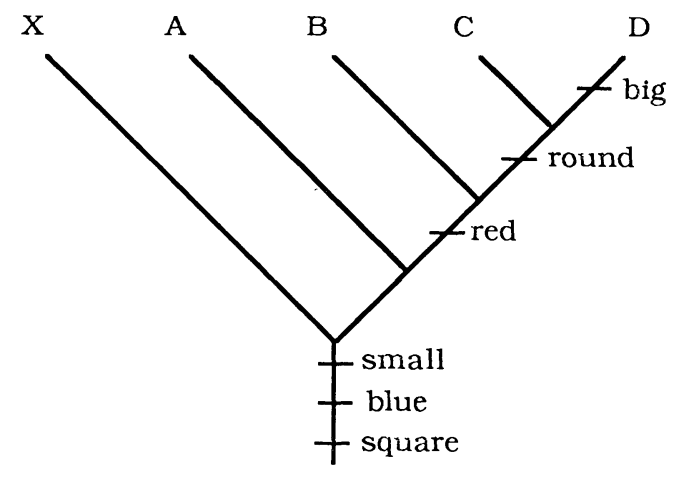

Fig. 3. Examining Adaptationist Hypotheses

Phylogenetic tree for the improbable species with the distribution of the three characters mapped onto it. 
TABLE 4

The distribution of male nuptial coloration among species within the family Gasterosteidae

\begin{tabular}{lc}
\hline Species & $\begin{array}{c}\text { Whole-body nuptial } \\
\text { coloration }\end{array}$ \\
\hline Spinachia spinachia & absent \\
Apeltes quadracus & absent \\
Pungitius pungitius & present \\
Culaea inconstans & present \\
Gasterosteus wheatlandi & present \\
Gasterosteus aculeatus & present \\
\hline
\end{tabular}

aculeatus are examined for the presence of whole-body nuptial coloration in breeding males, an interesting pattern appears (Table 4). We can optimize the character "male nuptial color: present or absent" onto a phylogenetic tree for the stickleback fishes in the following manner. Figure 4 depicts the phylogenetic tree for the Gasterosteidae (Paepke, 1983; McLennan et al., 1988). The distribution of the binary epigamic character is mapped at the ends of the branches, and the nodes are labeled for reference in Figures 5 to 7.

Step 1. Generalizing down the tree (Fig. 5): Label the two nodes that are farthest from the ingroup node in the following manner: (1) label the node $a$ if the two closest nodes or branches are either both a, or a and a,b; (2) label the node $\mathbf{b}$ if the two closest nodes or branches are either both $b$, or $b$ and a,b; (3) if the closest branches or nodes have different labels (one a and the other b), then label the node a,b. Continue working toward the ingroup node in this manner. Thus, beginning with the node connecting Gasterosteus aculeatus

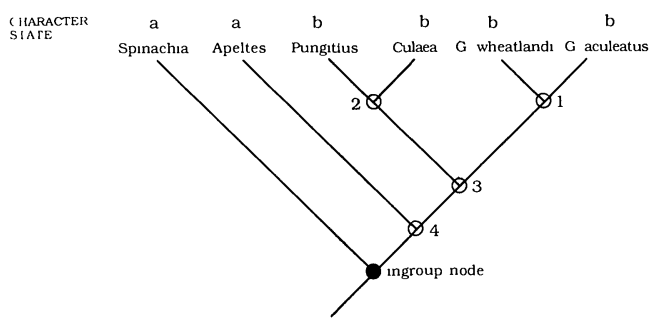

Fig. 4. Phylogenetic Tree for the Gasterosteidáe

a, body nuptial coloration absent; b, body nuptial coloration present. Nodes are labeled with numbers. and $G$. wheatlandi, both of which exhibit character $b$, we generalize that the nodal (ancestral) state is $\mathbf{b}$ (node 1). The argument is the same for the node connecting Pungitius and Culaea (node 2). Node 3 is the ancestor of nodes 1 and 2 , both of which are $\mathbf{b}$; therefore the state at this node is also b. Node 4 connects an a branch (Apeltes) with a b node (node 3 ); therefore, the state is ambiguous for $\mathbf{a}$ or $\mathbf{b}(\mathbf{a}, \mathbf{b})$. Finally, we assign a value of a to the ingroup node because it connects an a,b node and an a branch (Spinachia), so a wins out over b by majority vote (the principle of parsimony). It is important to note here that any ambiguity at the ingroup node may be resolved by reference to outgroups.

Step 2. Predicting up the tree (Fig. 6): Move from the ingroup node (Fig. 5) up the tree, resolving any ambiguity (i.e., node $4, \mathbf{a}, \mathbf{b}$ ) by comparing the value of the ambiguous node with the value of the node directly below it (ingroup node). In this example only node 4, designated a,b in Figure 5, is ambiguous. Since the value of the node below it is a, node 4 is reassigned state a. All nodal states have now been unambiguously resolved on the tree.

Character optimization thus provides the following evolutionary hypothesis for this binary character (Fig. 7): (1) the absence of whole-body male nuptial coloration (state a) is a persistent ancestral condition in two of the six terminal taxa (plesiomorphy); (2) there was a change from absent to whole-body, male nuptial coloration ( $a$ to $b$ ) in the ancestor of the Pungitius + Culaea + Gasterosteus wheatlandi + G. aculeatus clade.

Although we have now identified the evolutionary origin of the sexually dimorphic character, it is still necessary to determine the mech-

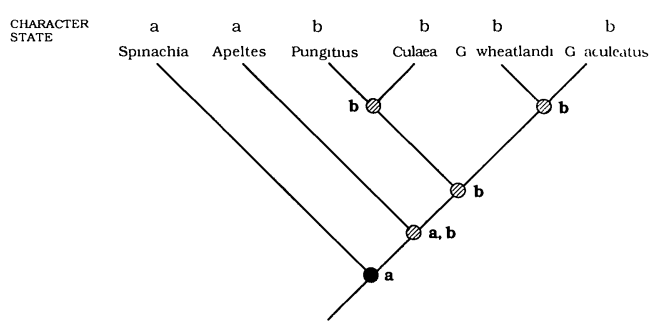

Fig. 5. Step 1 in Farris Optimization of a Binary Character: Generalize Down the Tree 


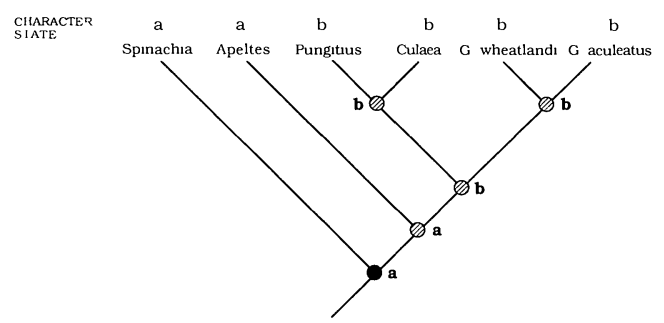

Fig. 6. Step 2 in Farris Optimization of a Binary Gharacter: Predict Up the TREE

anism underlying its appearance. Whole-body coloration occurs in the monophyletic group comprising Pungitius, Culaea, Gasterosteus, and their ancestor. Since its distribution is correlated with the phylogenetic relationships of these taxa, its presence in these species represents the persistence of an ancestral trait. Consequently, female choice experiments may uncover valuable information concerning the maintenance of sexual dimorphism under current environmental conditions; however, on their own, such experiments do not address why that character was originally successful. In order to explain this, we need an assessment of that ancestor's biology in its environment. Needless to say, since this assessment requires information about the social interactions in a (presumably) extinct ancestor, we cannot measure it directly. We can, however, use the optimization methods just described for uncovering the origin of sexual dimorphism, to determine whether female choice based upon that dimorphism originated at the same time. For example, McLennan and McPhail (1990) demonstrated that $G$. aculeatus females prefer more intensely colored males when given a choice between two suitors vying for their attention. If this preference is also demonstrated by female Pungitius, Culaea and G. wheatlandi, then we would have strong evidence that the initial elaboration of male color in the ancestor of the clade was driven by female preference for more intensely colored males.

Like many aspects of the natural world, optimization does not always produce unambiguous results (Swofford and Maddison, 1987; Donoghue, 1989; see also Brooks and McLen-

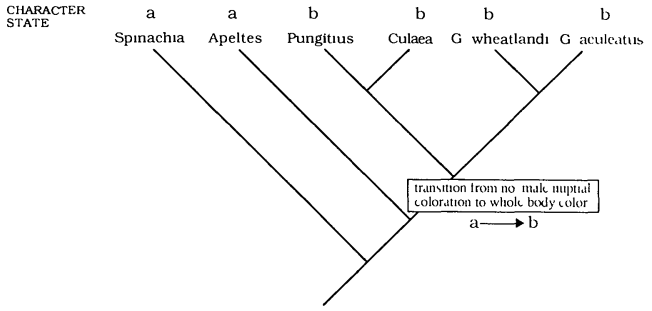

Fig. 7. Macroevolutionary Hypothesis about the Origin and Elaboration of Male Nuptial Coloration in the Gasterosteidae

nan, 1991 for a more detailed explanation of basic optimization procedures). In some systems, additional biological information (e.g., developmental or biochemical data) can be brought to bear on the problem. In other systems, we can attempt to evaluate the conflicting hypotheses of character evolution by direct experimental studies in both the field and the laboratory. Although we would like nature to provide us with a perfect record of evolution, this does not always happen. In such cases, we expect that phylogenetic optimization will tell us exactly where the ambiguity lies, even if it cannot provide an unambiguous interpretation.

\section{The Origin of Parasite-Host Association}

From a macroevolutionary perspective, there are two explanations for the occurrence of a given parasite in a given host; either the parasite inhabits the host because its ancestor was associated with the host's ancestor (association by descent; Mitter and Brooks, 1983) or because it evolved in association with a different host group and colonized the host of interest subsequent to its evolution (association by colonization; Mitter and Brooks, 1983). Any parasite species inhabiting two or more hosts may exhibit both types of associations. Clades that show historical association with other clades exhibit cospeciation (Brooks, 1979) patterns. A phylogenetic systematic method (Brooks, 1981, 1985, 1988, 1990; see also Cracraft, 1988; Kluge, 1988; Mayden, 1988; Wiley, 1988a,b) has been developed to distinguish association by descent from association by colonization in cospeciation studies. In general, it is important to dis- 


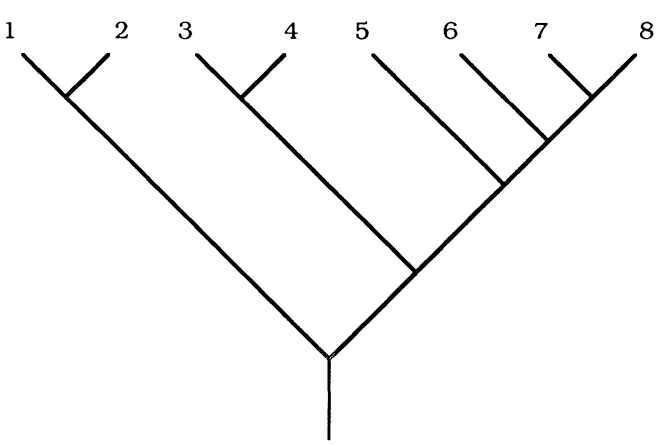

Fig. 8. Phylogenetic Tree for the Amphilinidea

1, Amphilina foliacea; 2, A. japonica; 3, Gigantolina elongata; 4, G. magna; 5, Schizochoerus paragonopora; 6, S. janickii; 7, S. liguloideus; and 8, S. africanus.

tinguish these two components in the origins of any ecological association if we are to understand the mechanistic implications of historical versus nonhistorical interactions (Brooks and McLennan, 1991). We hope to show that by understanding the evolutionary origins of host-parasite associations, one can distinguish those parasites that are relevant to the Hamilton-Zuk hypothesis from those that are not.

A simple example applies this method to an esoteric group of parasitic flatworms, the Amphilinidea. Amphilinids, the sister group of the species-rich true tapeworms, are a small (eight known species) but widespread group of parasites that live in the body cavities of freshwater and estuarine ray-finned fishes and in one spe-

TABLE 5

List of hosts and species of amphilinids that inhabit them

\begin{tabular}{lcl}
\hline Host & $\begin{array}{c}\text { Parasite } \\
\text { no. }\end{array}$ & \multicolumn{1}{c}{ Parasite name } \\
\hline Acipenseriformes & 1 & Amphilina foliacea \\
Acipenseriformes & 2 & Amphilina japonica \\
Perciformes & 3 & Gigantolina elongata \\
Chelonia & 4 & Gigantolina magna \\
Siluriformes & 5 & Schizochoerus paragonopora \\
Osteoglossiformes & 6 & Schizochoerus janickii \\
Osteoglossiformes & 7 & Schizochoerus liguloideus \\
Osteoglossiformes & 8 & Schizochoerus africanus \\
\hline
\end{tabular}

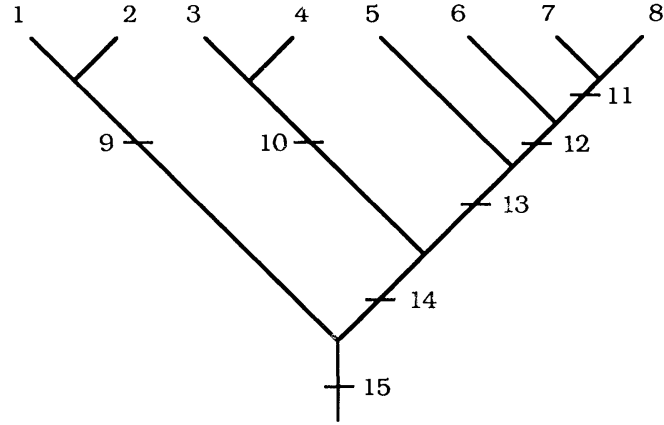

Fig. 9. Phylogenetic Tree for Eight Species of Amphilinid Flatworms With INTERNAL BraNGGES NUMBERED fOR Cospeciation Analysis

1, Amphilina foliacea; 2, A. japonica; 3, Gigantolina elongata; 4, G. magna; 5, Schizochoerus paragonopora; 6 , S. janickii; 7, S. liguloideus; 8, S. africanus; and 9-15, ancestral species.

cies of freshwater turtle. The first step is reconstruction of the phylogenetic relationships of the organisms. Phylogenetic systematic analysis of the amphilinids, based on 46 morphological characters, produced a single tree with a consistency index of 87.5 percent (Bandoni and Brooks, 1987) (Fig. 8). We then list the amphilinid species with their hosts (Table 5). The phylogenetic relationships of the eight amphilinid species can now be treated as if they were a completely polarized multistate transformation series, in which each taxon and each internal branch of the tree is numbered (Fig. 9). Each amphilinid species now has a code that indicates both its identity and its common ancestry. For example, the code for Amphilina

TABLE 6

Data matrix listing binary codes for the eight species of amphilinid flatworms

\begin{tabular}{lcc}
\hline & $\begin{array}{c}\text { Parasite } \\
\text { norasite name }\end{array}$ & Binary code \\
\hline Amphilina foliacea & 1 & 100000001000001 \\
Amphilina japonica & 2 & 010000001000001 \\
Gigantolina elongata & 3 & 001000000100011 \\
Gigantolina magna & 4 & 000100000100011 \\
Schizochoerus paragonopora & 5 & 000010000000111 \\
Schizochoerus janickii & 6 & 000001000001111 \\
Schizochoerus liguloideus & 7 & 00000010001111 \\
Schizochoerus africanus & 8 & 00000001001111 \\
\hline
\end{tabular}




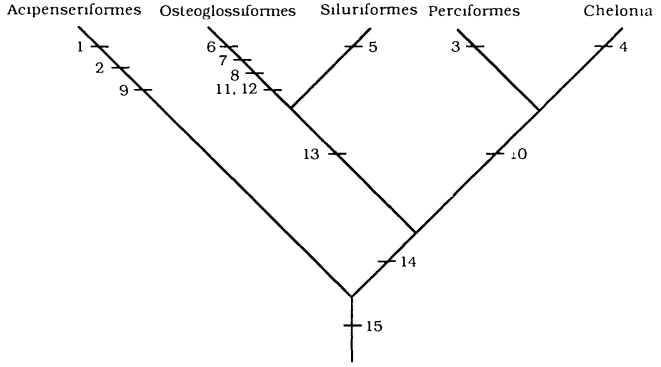

Fig. 10. Host Cladogram Based on Phylogenetic Relationships of Amphillinid Flatworm Parasites

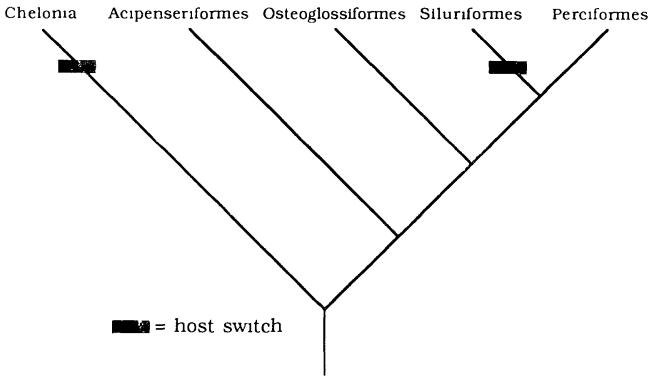

Fig. 11. Phylogenetic Tree for the Hosts of the Eight Amphilinid Spegies

Incongruencies between the host cladograms of Figure 10 and the phylogenetic tree of Figure 11 are hypothesized to represent instances of host switching. Congruent portions of the two trees represent instances of cospeciation between the host and the parasite.

japonica (Parasite No. 2) is $(2,9,15)$ and the code for Schizochoerus africanus is $(8,11,12,13,14,15)$. These codes can be represented in a data matrix in which the presence of a number in the species code is listed as " 1 " and the absence of a number in the species code is listed as " 0 " (Table 6). The phylogenetic relationships of the amphilinids can thus be represented by binary codes. Now we replace the name of each parasite species in Table 6 with the name of its associated host group (Table 7). Finally, we construct a host cladogram based on the phylogenetic relationships of the parasite species (Fig. 10). This produces a picture of the historical association between the parasites and their hosts.

We can now compare the host cladogram reconstructed from the phylogenetic relationships of the parasites with the cladogram based

\section{TABLE 7}

Matrix of hosts for amphilinid flatworms and the binary codes for the parasites and their phylogenetic relationships

\begin{tabular}{lcc}
\hline Host & Parasite no. & Binary code \\
\hline Acipenseriformes & 1 & 100000001000001 \\
Acipenseriformes & 2 & 010000001000001 \\
Perciformes & 3 & 001000000100011 \\
Chelonia & 4 & 000100000100011 \\
Siluriformes & 5 & 000010000000111 \\
Osteoglossiformes & 6 & 000001000001111 \\
Osteoglossiformes & 7 & 000000100011111 \\
Osteoglossiformes & 8 & 000000010011111 \\
\hline
\end{tabular}

upon characteristics of the hosts themselves. Congruence between the two cladograms indicates the portion of the host-parasite system that can be explained by phylogenetic association (i.e., their ancestors were associated), whereas incongruence highlights cases of host switching. For example, the amphilinids inhabiting acipenseriforms are a monophyletic group, as are those inhabiting osteoglossiforms. The turtle Chelodina longicollis, however, is not the sister group of perciform teleostean fishes, so we must interpret the presence of Gigantolina magna (character 4 in Fig. 10) in $C$. longicollis as the result of a host switch. In addition, contrary to the current phylogenetic analysis of the actinopterygians, this cladogram places siluriform fishes with the osteoglossiforms rather than with the perciforms; therefore, the presence of Schizochoerus paragonopora (character 5 in Fig. 10) in a siluriform host must be the result of a host switch as well. So, the evolution of the eight extant amphilinids has involved six cases of phylogenetic association with their hosts and two cases of host switching (Fig. 11).

We now turn our attention specifically to the Hamilton-Zuk hypothesis. Since this hypothesis is about mechanisms of evolutionary change, it should make predictions about the evolutionary origins of, and associations among, characters through time. In this case, the characters are male epigamic traits and host-parasite associations. Unfortunately, there are very few phylogenies available for parasite groups, and of these, none are for parasites that 


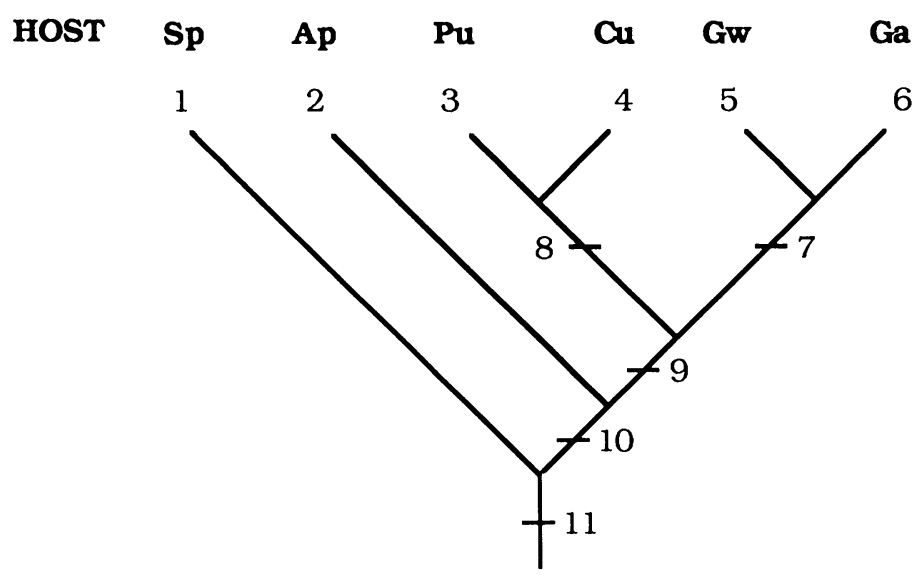

( a )

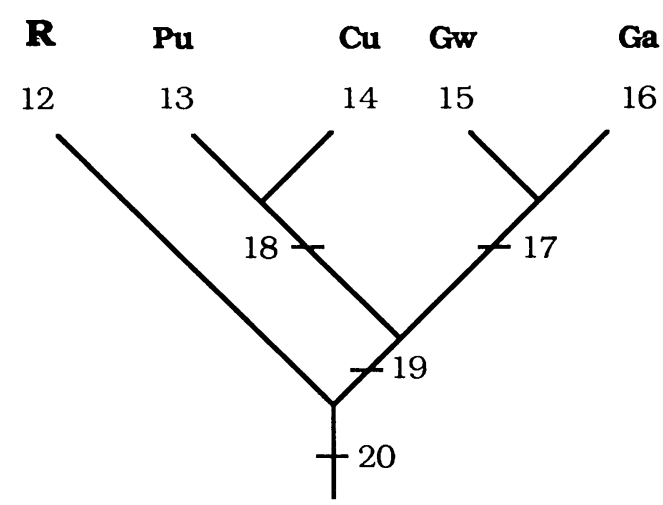

( b )

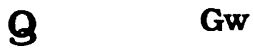

Ga

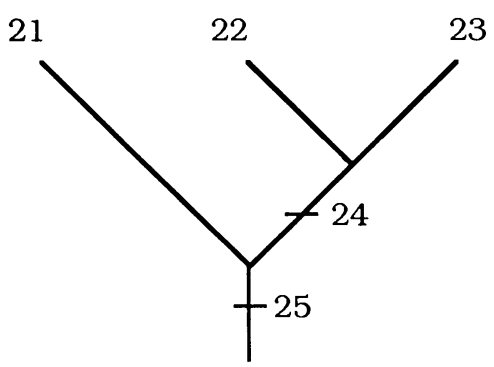

( c )

Fig. 12. Phylogenetic Trees for Three Hypothetical, but Monophyletic, Groups of Parasites

(a) Tapeworms living in the upper intestine of gasterosteid fishes. (b) Monogeneans living on the body of the monophyletic group $\mathbf{R}$ and some members of the Gasterosteidae. (c) Nematodes living in the intestine of the monophyletic group $\mathbf{Q}$ and some members of the Gasterosteidae. Hosts: $\mathbf{R}$, a monophyletic group of theoretical trout species; $\mathbf{Q}$, a monophyletic group of theoretical blenny species; Sp, Spinachia spinachia; Ap, Apeltes quadracus; Pu, Pungitius pungitius; Cu, Culaea inconstans; Gw, Gasterosteus wheatlandi; and $\mathbf{G a}, G$. aculeatus.

have interested students of the Hamilton-Zuk hypothesis. For the sake of illustration, let us consider the Gasterosteidae and their associations with a hypothetical group of tapeworms, monogeneans and nematodes. The phylogenetic relationships of these parasites, numbered for phylogenetic analysis, are depicted in Figure 12. This produces the host cladogram shown in Figure 13.

According to this analysis, the tapeworms (characters 1-11) originated with the ancestor of the stickleback fishes (association by descent), and speciated along with their host group (cospeciation). The monogeneans (characters 12-20) are present because of a host switch (association by colonization) by ancestor 20 from the monophyletic group $\mathbf{R}$ to the ancestor of the Pungitius + Culaea + Gasterosteus clade. Once the host switch had occurred the monogenean ancestor speciated, producing 
descendant 19, and the remainder of the parasite phylogeny is congruent with the gasterosteid speciation pattern (cospeciation). Finally, the presence of the nematodes (characters 21-25) also resulted from a host switch, in this case from the monophyletic group $\mathbf{Q}$ to the ancestor of Gasterosteus wheatlandi and G. aculeatus. When that ancestor (24) speciated, so did the ancestral nematode, producing descendants 22 and 23 in their respective hosts. Thus, each of the three parasite groups began its association with gasterosteids at a different time. Now, consider the origin of the three stickleback-parasite associations in relation to the origin of the sexually dimorphic character "whole-body nuptial coloration" as shown in Figure 14.

There are three types of macroevolutionary associations delineated in this figure. First, the host-parasite association appears before the origin of the sexually selected character (tapeworms and sticklebacks). In this scenario, the host and parasite have shared a long history of cospeciation. Although researchers are just beginning to ask questions about the relationship between parasite virulence and the age of the host-parasite association, the working assumption is that tightly cospeciated groups will fall at the low end of the Anderson and May virulence scale. Because of this, by the time the sexually dimorphic character appeared in the ancestor of the Pungitius + Culaea + Gasterosteus clade, the tapeworm associated with this ancestor would be hypothesized to have only a minor effect on host health. Past this point, the host-parasite interaction would continue to move toward minimal virulence, so by the time Pungitius, Culaea, and Gasterosteus appeared, the dynamic between host, parasite, male color, and female choice would be further weakened, rendering it less likely that a female choosing males based upon color would also be choosing mates demonstrating a superior ability to resist invasion and damage from the appropriate tapeworm species. If these assumptions

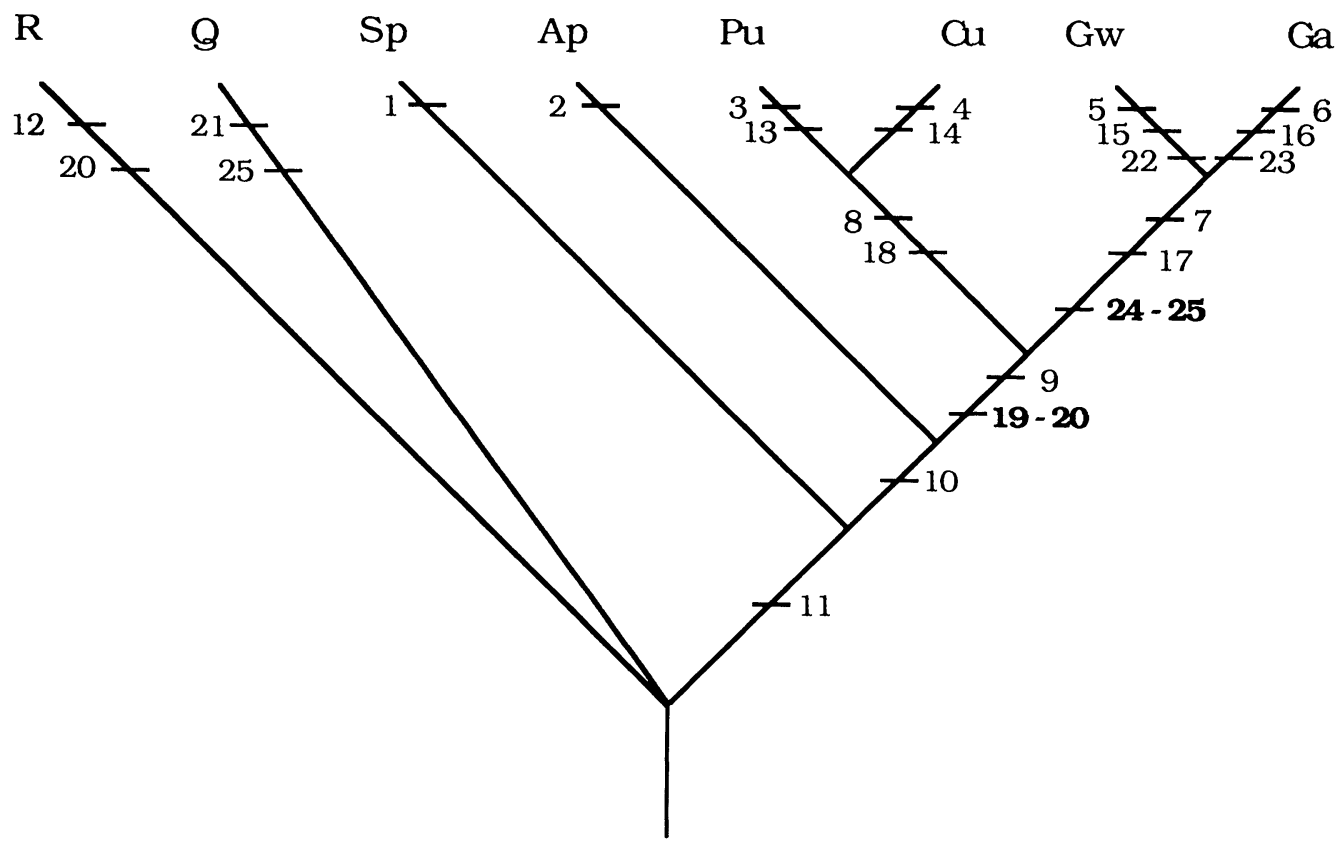

Fig. 13. Phylogenetic Tree for the Hosts Regonstructed from the Parasite Data

Numbers refer to the three parasite phylogenies depicted in Figure 12: tapeworms (characters 1-11), monogeneans (characters 12-20) and nematodes (characters 21-25). Bold numbers indicate instances of presumptive host switching. Hosts: $\mathbf{R}$, a monophyletic group of theoretical trout species; $\mathbf{Q}$, a monophyletic group of theoretical blenny species; Sp, Spinachia spinachia; Ap, Apeltes quadracus; Pu, Pungitius pungitius; $\mathbf{C u}$, Culaea inconstans; Gw, Gasterosteus wheatlandi; and $\mathbf{G a}, G$. aculeatus. 


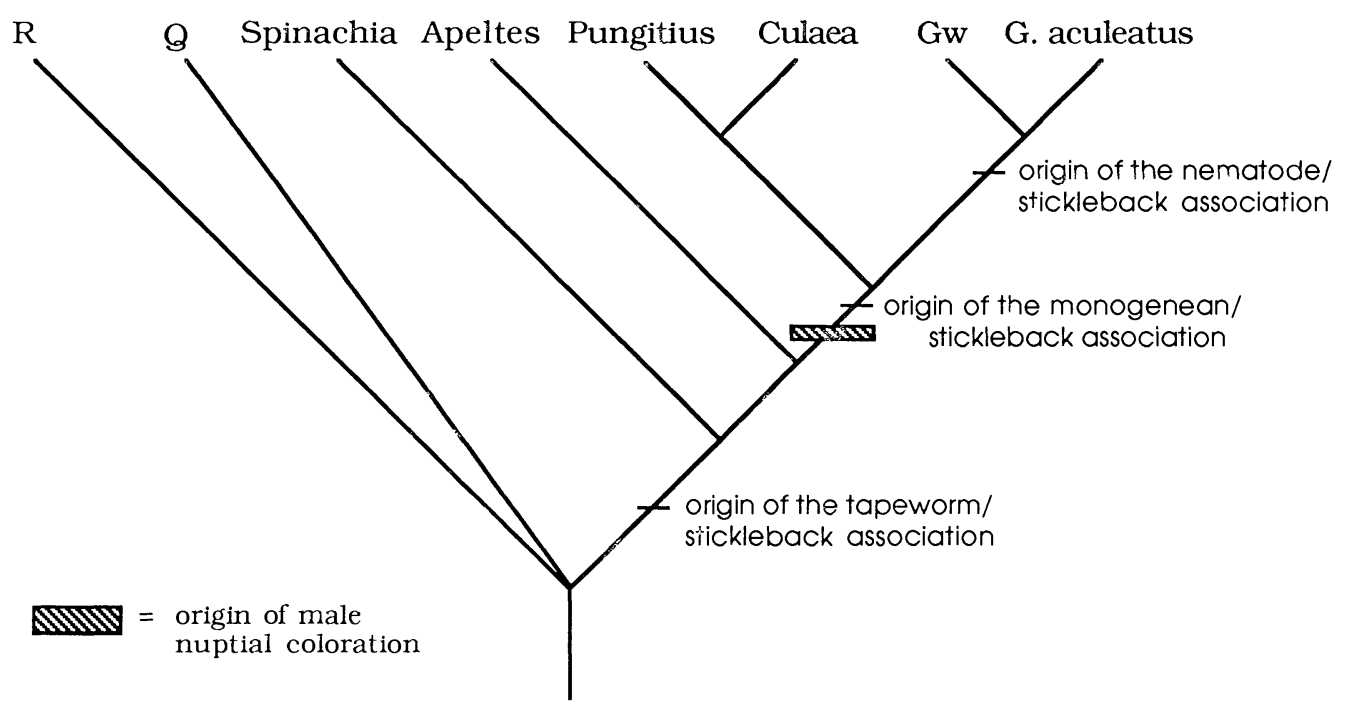

Fig. 14. Origins of Host-Parasite Associations and Male Nuptial Coloration in Gasterosteidae, Gw, Gasterosteus whealiandi

about parasite pathology anc the age of the host-parasite association are correct, then this type of pattern provides, at best, weak suppont for the Hamilton-Zuk hypothesis. Second, the host-parasite association originated in the same species in which the sexuaily cimorp.ic trait arose (monogeneans and sticklebacks). In this scenario, the appearance of a new parasite species in a host species (by a host. switch) is accompanied by the appearance oi the sexually selected character in the host. Since host switches are presumed to be accompanieci by more virulent adaptive-coadaptive cycing between the parasite and its new host (Stock anci Holmes, 1987), both the macroevolutionary pattern and the biological interactions assumed to underlie such a pattern provide strong support for the Hamilton-Zuk hypothesis. And third, the host-parasite association originates after the sexually selected character (nematodes and sticklebacks). This pattern refutes the hypothesis that the interaction between the hostparasite dynamic and female choice for a naie character reflecting that ciynamic is chiving the initial elaboration of the mele character. Although this tells us nothing about the mechanism of sexua! selection, it does not rule out the possibility that this interaction is positively reinforcing the mechanism once it occurs.
Overall, there are four potential macroevolutionary patterns, two of which support [Figs. 15(b) and 15(d)], and two of which refute [Figs. 15(a) and 15(c)] the hypothesis that there is an evolutionary interaction between the presence of parasites and the development of sexual cimorphism in the study group. Since the sequence of character origin cannot be determined without a phylogeny, a macroevolutionary analysis is a critical first step in distinguishing between systems that will, and those that will not, provide a strong test of the HamiltonZuk hypothesis. For example, suppose a researcher decided to investigate a host species because it was "sexually dimorphic" and "had parasites." If this species was like $\mathrm{Y}$ and $\mathrm{Z}$ in Figure 15(c), this investigator would either (1) uncover a significant association between parasite burden and degree of male epigamic deveiopment and incorrectly conclude that the Hamilton and Zuk mechanism was involved in the initial elaboration of the male character, or (¿) uncover no association and correctly conclude that the hypothesis was not supported for this group. If, however, phylogenies had been available prior to the experiments (and this is currently a large "if"), the researcher could have determined that the epigamic trait originated prior to the host-parasite association, rejected 
the hypothesis on macroevolutionary grounds, and saved the time and expense of running the experiment.

The strongest macroevolutionary evidence for the Hamilton-Zuk hypothesis comes from cases in which a host switch coincides with the origin of the sexually selected trait. The proposal that host switches are an important component of the hypothesis complies with the assumption that the interaction between the host and parasite represents a coevolutionary armsrace dynamic. There are, however, two general classes of coevolutionary models that address the influence of host switching on host-parasite interactions, only one of which involves a specific cycling of mutual modification, or reciprocal adaptation, of the population ecology or population genetics of the ecologically associated species. Resource tracking (or colonization) coevolutionary models are based on the concept that hosts represent patches of necessary resources that associates have "tracked" through evolutionary time (Kethley and Johnston, 1975). In this case, the diversification of the associated taxa occurs independently, since this host switching involves the "tracking" of a

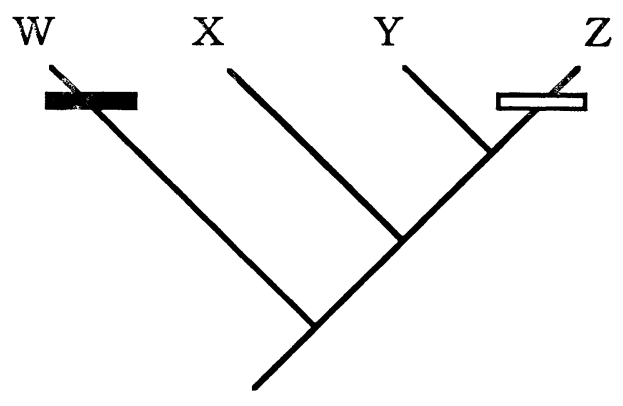

( a )

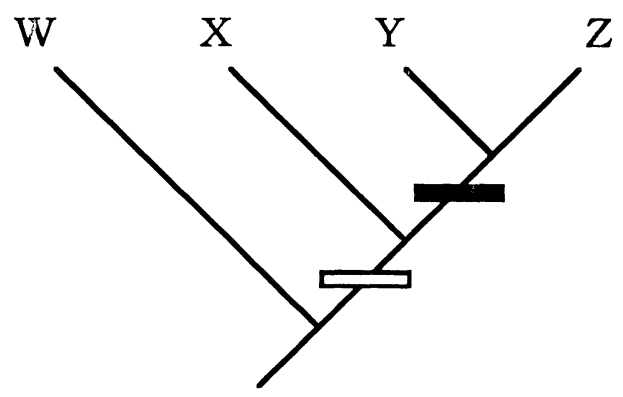

( c )

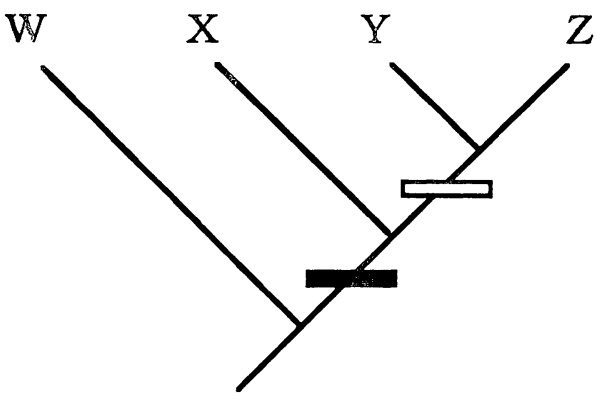

( b )

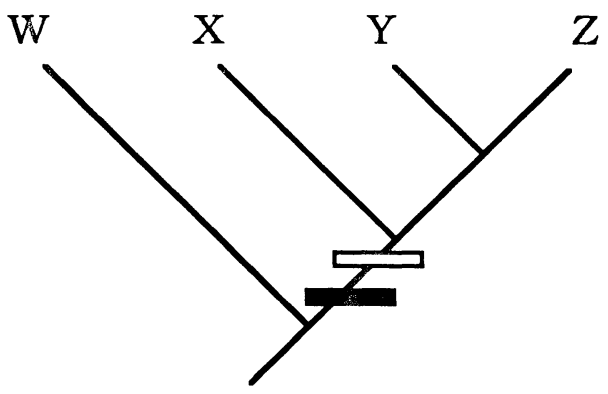

(d)

Fig. 15. Examining Phylogenetic Relationships between Two Different Charagters

Biack boxes, origin of the host-parasite association; white boxes, origin of the sexually selected trait. (a) The host-parasite association and the sexually selected trait arose independently in different species; the traits neither co-originate nor co-occur. (b) The host-parasite association arose before the sexually dimorphic trait; the traits do not co-originate but they do co-occur in some members of the group. (c) The sexually selected trait arose before the host-parasite association; the traits do not co-originate but they do co-occur in some members of the group. (d) Both characters originated in the same ancestor; the traits co-originate and co-occur. Patterns (a) and (c) refute the Hamilton-Zuk hypothesis, pattern (b) provides weak support ard pattern (d) provides strong support for the hypothesis. 


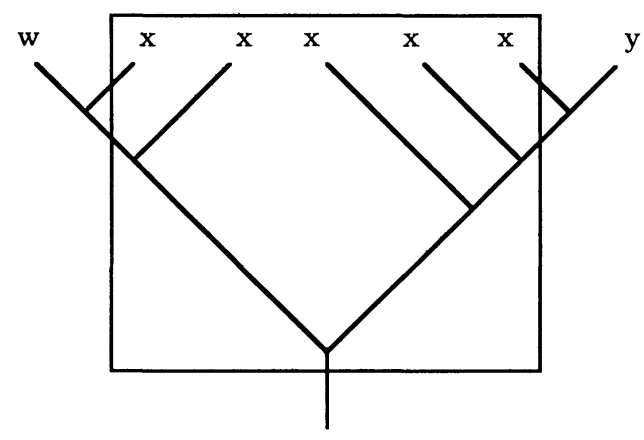

( a ) RESOURCE IS PLESIOMORPHIC

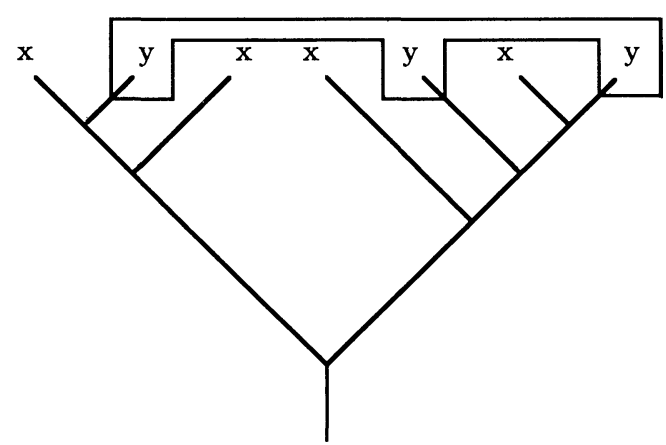

( b ) RESOURCE IS CONVERGENT

Fig. 16. Sequential Colonization Model

(a) Target area for colonization sequences (enclosed within the box) if the resource being used is plesiomorphic and widespread. (b) Target area for colonization sequences if the resource being used is convergent and widespread (from Brooks and McLennan, 1991).

resource that is shared among a group of hosts that do not form a clade. For example, the sequential colonization model (Jermy 1976, 1984), originally designed to explain insectplant coevolution, proposes that the diversification of phytophagous insects took place after the radiation of their host plants. The insects are hypothesized to have colonized new host plants many times during their evolution. In each case the colonization was the result of the evolution of insects responding to a particular biotic resource that already existed in at least one plant species. That resource, in turn, is postulated to have been either plesiomorphi- cally [Fig. 16(a)] or convergently [Fig. 16(b)] widespread.

The evolutionary arms race is the classical coevolution model developed by Ehrlich and Raven (1964) for phytophagous insects and plant systems (see also Mode, 1958; Feeny, 1976; Berenbaum, 1983; Futuyma and Slatkin, 1983). The primary assumption in "arms-race" models is that coevolving ecological associations are maintained by mutual adaptive responses. For example, it is possible that during the course of evolution, novel traits arise that "protect" the host from the effects of the parasite. It is also possible that traits countering such "defense mechanisms" may evolve in the parasite lineage. Evolutionary arms-race models generally assume that the time scale on which the "defense" and "counterdefense" traits originate in response to reciprocal selection pressure is longer than the time between speciation events. As a result, we might expect to find macroevolutionary patterns in which the parasite group is missing from most members of the host clade characterized by possession of the "defense" trait (Fig. 17). A second possi-

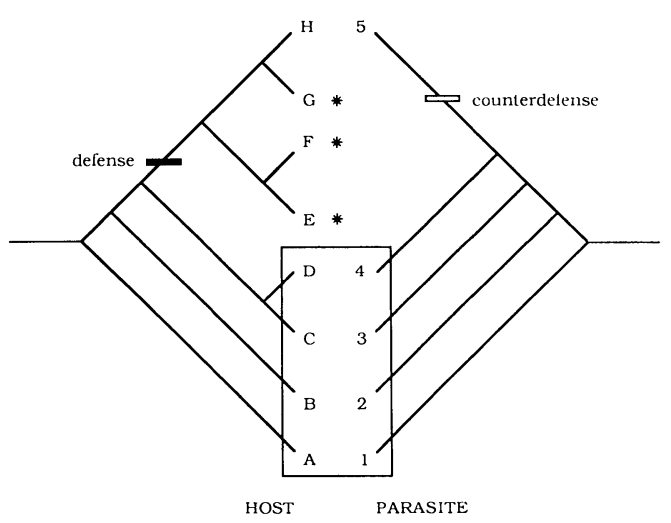

Fig. 17. Evolutionary Arms-Rage Type I

The host and parasite phylogenies are congruent (enclosed within the box) up to the point at which the defense trait appears. If the origination of a counterdefense lags behind this, and if the hosts continue to speciate, parasite species will be prohibited from interacting with any of the new host species (marked with an asterisk). Once a counterdefense appears, the host and parasite phylogenies rejoin (parasite species 5 switches from host species D to host species $\mathrm{H}$ ) and the cycle continues (from Brooks and McLennan, 1991). 


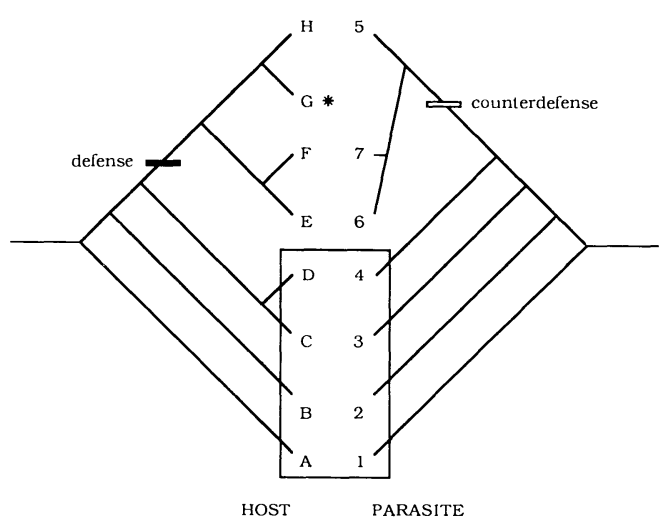

Fig. 18. Evolutionary Arms-Rage Outcome II

Once the counterdefense trait has appeared in the parasite lineage, continued speciation will produce new species capable of colonizing host species bearing only the old defense. The situation depicted here is an intermediate version of the large number of possible patterns which may be produced; ranging from all parasites bearing the counterdefense trait (species 5,6 and 7) back colonizing on all members of the host lineage, to no back colonization (from Brooks and McLennan, 1991).

ble macroevolutionary pattern results when one or more relatively plesiomorphic members of a host clade are colonized by more recently derived members of the parasite group bearing the "counterdefense" trait. In this case, host and parasite phylogenies will demonstrate some degree of incongruence and we would expect to find evidence that some parasites have "back colonized" hosts in the clade diagnosed by the presence of the "defense" trait (Fig. 18).

It is important to realize that one macroevolutionary outcome of an arms-race dynamic is the production of parasite-free hosts, i.e., hosts that "won" the arms race. The discovery of parasite-free, but sexually dimorphic host species would not appear, at first glance, to support the Hamilton-Zuk hypothesis. However, consider the situation depicted in Figure 19. In this scenario, the appearance of a new parasite counterdefense character is associated with a host shift by the new parasite species from the old host (species A) to a new host (ancestor $z$ ). This host switch, in turn, is associated with the appearance and elaboration of a sexually selected character in ancestor $z$. At this point in the phylogeny we have strong macroevolu- tionary evidence supporting the Hamilton-Zuk hypothesis. The interaction between a hostparasite arms-race dynamic and female choice for a male character reflecting that dynamic is transmitted from ancestor $z$ to three of its descendants, species $\mathrm{D}$ and the ancestor of species $\mathrm{E}+\mathrm{F}$, and species $\mathrm{E}$, maintaining sexual dimorphism in those species. A novel defense character appears in species $\mathrm{F}$, allowing the host to win the arms race with the parasite, for the time being. This, in turn, should eventually disrupt the parasite-driven sexual selection dynamic as less information about male quality is incorporated in the male signal. The time required for this decay, however, will depend upon a variety of factors, including the initial strength of the interaction (i.e., costs versus benefits of choice for both males and females), the degree of development of the male character, and the genetic-developmental constraints upon changes in the male character. Since this process will be very system dependent, we must consider two alternative explanations for the existence of a parasite-free, sexually dimorphic species F: (1) something other than the Hamilton-Zuk dynamic is maintaining sexual dimorphism in this species, or (2) insufficient time has passed for us to see the predicted decay in the relationship between the intensity of the male signal and male quality.

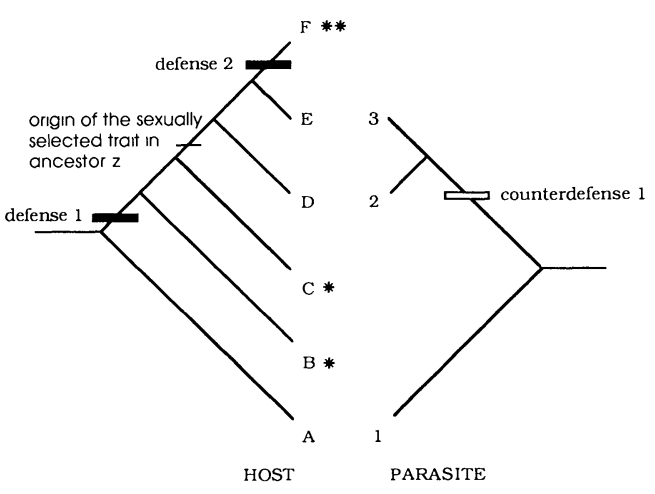

Fig. 19. One Possible Outcome of an Evolutionary Arms-Race ScEnario

*, parasite absent because this host developed defense 1 trait, and was never back colonized by the parasite species bearing the counterdefense 1 trait; **, parasite absent because this host developed defense 2 trait and there are no extant parasite species bearing the appropriate counterdefense. 
In summary, any given episode of association by colonization could be due to an armsrace dynamic if phylogenetic patterns of host switching are correlated with the origins of particular defense and counterdefense traits, or such episodes could be due to a resource-tracking dynamic if the required resource exhibits a plesiomorphic or convergent distribution among hosts (see Brooks and McLennan, 1991 for a more extensive discussion of macroevolutionary correlates of coevolutionary models). It is important to distinguish between the two types of host switching because they carry very different implications for the theoretical foundations of the hypothesis. If a macroevolutionary analysis demonstrates that the host switch correlated with the appearance of the sexually selected trait fits a resource-tracking model, then we cannot assume a priori that there is a cycle of adaptation or coadaptation occurring in the host-parasite association. On its own, then, this type of pattern does not provide support for the Hamilton-Zuk hypothesis. If, on the other hand, the host switch represents an instance of the evolutionary arms race, then we have strong macroevolutionary support for the existence of the tight coadaptive interaction between host and parasite required by the hypothesis.

Here we would point out that there are two important gaps in our knowledge. First, there is a profound asymmetry between research on the patterns and the processes of coevolution. Most of the models of coevolution are based on microevolutionary (population genetical and population ecological) processes. This state of affairs is hardly surprising, given the wealth of experimental and field data available at that level; compared to these studies, the number of studies investigating macroevolutionary patterns comes in a distant, but nevertheless optimistic, second. This asymmetry is beginning to disappear as the methods for uncovering the macroevolutionary patterns and for delineating the relationship between these patterns and the underlying processes are developed. Second, research at the population level continues to center around the arms-race model, while studies investigating the dynamics of the resource tracking or cospeciation components of an evolutionary association are vanishingly small. At the moment, we have very little information about the difference, if any, in the relationship between the degree of pathology and (1) the age of the host-parasite relationship and (2) the type of host switch. This information is crucial to the development of a strong coevolutionary theory, and to the understanding of how particular coevolutionary events may interact with the other evolutionary forces operating on that system.

\section{SUMMARY}

It has not been our purpose in this paper to discuss the validity of the Hamilton-Zuk hypothesis. Like any scientific idea, that question can only be resolved by the collection of large databases, and at the moment those databases are limited. We have, instead, taken the stand that the hypothesis is interesting and important, and thus deserves the most critical, rigorous evaluation available to researchers. Such an evaluation will enable us to uncover systems in which the Hamilton-Zuk dynamic has played an important role in the evolution of epigamic characters. This, in turn, will allow us to begin assembling a picture of the relative influence of both Fisherian and "good genes" intersexual selection on such evolution.

In conclusion, we provide a protocol that depicts the critical components in any study of the Hamilton-Zuk hypothesis. Such studies will require both time and the cooperation of ethologists, parasitologists and systematists. The first requirement is not new to ethology, since all good studies require a healthy dollop of time and patience. The second requirement will send one upon a quest for the golden fleece of science, cooperation among researchers. Hamilton and Zuk have woven the threads of many research programs into a general hypothesis, the utility of which depends upon the strength of each thread. We need phylogenies for the host and parasite groups, evidence for intersexual sexual selection, and integrated studies of the patterns and processes of coevolution. The result of such a quest will be, minimally, the identification of systems conforming to Hamilton and Zuk's predictions, and maximally, the development of a more profound understanding of the unifying concept in biology: evolution.

\section{A Hierarchical Protocol for Identifying Appropriate Systems for Analysis of the Hamilton-Zuk Hypothesis}

(1) Find sets of sister groups, one of which is, and the other of which is not, sexually di- 
morphic. Perform experimental tests to determine the selective regime maintaining that sexual dimorphism (i.e., establish the existence of female choice based upon the sexually dimorphic character).

(2) For the subset displaying female choice for the appropriate character, perform a phylogenetic analysis of the host group to establish the patterns of origin and diversification of the male epigamic trait.

(3) Perform a phylogenetic anaiysis of the hostparasite associations to determine which associations began before, during and after the origin of the male epigamic trait. Identify episodes of cospeciation, resource tracking and the evolutionary arms race.

Steps (1) to (3) identify the host-parasite systems that will provide the most rigorous test of the bypothesis.

(4) Having identified species in which the epigamic trait and host-parasite association cooriginate, perform the appropriate experiments to determine whether there is a correlation between the intensity of parasitism and the degree of development of the male character. Notice that we have already demonstrated in Step 2 that females choose mates based upon the degree of epigamic development.
(5) For the subset of the species demonstrating a positive correlation between male parasite load, epigamic development and female choice, determine:

(a) Demography of resistance (prevalence and intensity data),

(b) Heritability of resistance,

(c) Mechanistic basis of resistance,

(d) Relationship between parasite load and host health and vigor.

Steps (4) and (5) identify species in which the interaction between hosts and parasites has been incorporated into an intersexual selection dynamic. These species will provide the strongest test systems for investigating the mechanisms underlying this dynamic.

\section{ACKNOWLEDGMENTS}

We would like to thank Sherwin S. Desser, whose interest in the original paper by Hamilton and Zuk sparked an enthusiastic discussion group and provided us with a forum in which to present our ideas. Thanks are also due Sherwin Desser (again), Eric Hoberg, and Marlene Zuk for their thoughtiul and positive comments and criticisms of the original manuscript. This research was supported by a Natural Sciences and Engineering Research Council of Canada operating grant (No. A7696) to D. R. B.

\section{REFERENCES}

Anderson, R. C. 1976. Helminths. In L. A. Page (ed.), Wildlife Diseases. Section II. Impact of Parasitic Diseases on Wildlife Populations, pp. 35-43. Plenum Press, New York.

Anderson, R. M. 1982. Host-parasite population biology. In D. F. Mettrick and S. S. Desser (eds.), Parasites - Their World and Ours, pp. 303-312. Elsevier Biomedical Press, Amsterdam.

Anderson, R. M., and D. M. Gordon. 1982. Processes influencing the distribution of parasite numbers within host populations with special emphasis on parasite-induced host mortalities. Parasitology, 85: 373-398.

Anderson, R. M., and R. M. May. 1978. Regulation and stability of host-parasite population interactions. I. Regulatory processes. J. Anim. Ecol., 47: 219-247.

— and - 1979. Prevalence of schistosome infections within molluscan populations: observed patterns and theoretical predictions. Parasitology, 79: 63-94.

— and - 1982. Coevolution of hosts and parasites. Parasitology, 85: 411-426. $\longrightarrow$, and - 1985. Epidemiology and genetics in the coevolution of parasites and hosts. Proc. $R$. Soc. Lond. B Biol. Sci., 219: 281-283.

Andersson, M. 1982. Sexual selection, natural selection and quality advertisement. Biol. J. Linn. Soc., 17: 375-393.

- 1986. Evolution of condition-dependent sex ornaments and mating preferences: sexual selection based on viability differences. Evolution, 40: 804-816.

Arme, C., and R. Wynne Owen. 1967. Infections of the three-spined stickleback, Gasterosteus aculeatus L., with the plerocercoid larvae of Schistocephalus solidus (Muller, 1776), with special reference to pathological effects. Parasitology, 57: 301-314.

Bandoni, S. M., and D. R. Brooks. 1987. Revision and phylogenetic analysis of the Amphilinidea Poche, 1922 (Platyhelmin thes: Cercomeria: Cercomeromorpha). Can. J. Zool., 65: 1110-1128.

Bennett, G. F., J. Blancou, E. M. White, and N. A. Williams. 1978. Blood parasites of some birds from Senegal. J. Wildl. Dis., 14: 67-73.

Bennett, G. F., E. C. Greiner, and W. Threlfall. 1976. 
Protozoans. In L. A. Page (ed.), Wildlife Diseases. Section II. Impact of Parasitic Diseases on Wildlife Populations, pp. 25-33. Plenum Press, New York.

Berenbaum, M. R. 1983. Coumarins and caterpillars: a case for coevolution. Evolution, 37: 163-179.

Blower, S. M., and J. Roughgarden. 1989. Parasites detect host spatial pattern and density: a field experimental analysis. Oecologia, 78: 138-141.

Borgia, G. 1979. Sexual selection and the evolution of mating systems. In M. S. Blum and M. A. Blum (eds.), Sexual Selection and Reproductive Competition in Insects, pp. 19-80. Academic Press, New York.

- 1986. Satin bowerbird parasites: a test of the bright male hypothesis. Behav. Ecol. Sociobiol., 19: 355-358.

Borgia, G., and K. Collins. 1989. Female choice for parasite-free male satin bowerbirds and the evolution of bright male plumage. Behav. Ecol. Sociobiol., 25: 445-454.

Bradbury, J. W., and M. B. Andersson (eds.). 1987. Sexual Selection: Testing the Alternatives. John Wiley and Sons, London.

Brandt, B. B. 1936. Parasites of certain North Carolina salientia. Ecol. Monogr., 6: 491-532.

Brooks, D. R. 1976. Parasites of amphibians of the Great Plains, II. Platyhelminths of amphibians in Nebraska. Bull. Univ. Nebr. State Mus., 10: 65-92.

- 1979. Testing the context and extent of hostparasite coevolution. Syst. Zool., 28: 299-307.

—. 1981. Hennig's parasitological method: a proposed solution. Syst. Zool., 30: 229-249.

- 1985. Historical ecology: a new approach to studying the evolution of ecological associations. Ann. Mo. Bot. Gard., 72: 660-680.

- 1988. Macroevolutionary comparisons of host and parasite phylogenies. Annu. Rev. Ecol. Syst., 19: 235-259.

- 1990. Parsimony analysis in historical biogeography and coevolution: methodological and theoretical update. Syst. Zool., 39: 14-30.

Brooks, D. R., and D. A. McLennan. 1991. Phylogeny, Ecology and Behavior: A Research Program in Comparative Biology. The University of Chicago Press, Chicago.

Calentine, R. L. 1967. Larval development of four caryophyllaeid cestodes. Proc. Iowa Acad. Sci., 72: 418-424.

Castro, G. A., and L. J. Olson. 1967. Relationship between body weight and food and water intake in Trichinella spiralis-infected guinea pigs. J. Parasitol., 53: 589-594.

Castro, G. A., L. J. Olson, and R. D. Baker. 1967. Glucose malabsorption and intestinal histopathology in Trichinella spiralis-infected guinea pigs. J. Parasitol., 53: 595-612.

Cheverud, J. M., M. M. Dow, and W. Leuteneg- ger. 1985. The quantitative assessment of phylogenetic constraints in comparative analyses: sexual dimorphism in body weight among primates. Evolution, 39: 1335-1351.

Clutton-Brock, T. H., and P. H. Harvey. 1984. Comparative approaches to investigating adaptation. In J. R. Krebs and N. B. Davies (eds.), Behavioural Ecology: An Evolutionary Approach. 2nd ed., pp. 729. Sinauer Associates, Sunderland.

Cohen, J. E., and C. M. Newman. 1989. Hostparasite relations and random zero-sum games: the stabilizing effect of strategy diversification. Am. Nat., 133: 533-552.

Collins, W. E., J. C. Skinner, M. Pappaioanou, N. Shui-Fong Ma, J. R. Broderson, B. B. Sutton, and P. S. Stanfill. 1987. Infection of Aotus vociferans (Karyotype V) monkeys with different strains of Plasmodium vivax. J. Parasitol. , 73: 536540.

Cone, D. K., and P. H. Odense. 1984. Pathology of five species of Gyrodactylus Nordmann, 1932 (Monogenea). Can. J. Zool., 62: 1084-1088.

Courtney, C. C., and B. M. Christensen. 1987. Hostparasite relationships of caryophyllaeid cestodes and aquatic oligochaetes: I. Host longevity and parasite intensity. J. Parasitol., 73: 1124-1132.

$\longrightarrow$, and - 1988 . Host-parasite relationships of caryophyllaeid cestodes and aquatic oligochaetes: II. Effects of host age and mixed infections. J. Parasitol., 74: 573-581.

Cox, F. E. G. 1989. Parasites and sexual selection. Nature, 341: 289.

Cracraft, J. 1988. Deep-history biogeography: retrieving the historical pattern of evolving continental biotas. Syst. Zool., 37: 221-236.

Crews, A. E., and G. W. Esch. 1986. Seasonal dynamics of Halipegus occidualis (Trematoda: Hemiuridae) in Helisoma anceps and its impact on the fecundity of the host snail. J. Parasitol., 72: 646-651.

Crump, M. L., and J. A. Pounds. 1985. Lethal parasitism of an aposematic anuran (Atelopus varius) by Notochaeta bufonivora (Diptera: Sarcophagidae). J. Parasitol., 71: 588-591.

Cusack, R. 1986. Development of infections of $G y$ rodactylus colemanensis Mizelle and Kritsky, 1967 (Monogenea) and the effect on fry of Salmo gairdneri Richardson. J. Parasitol., 72: 663-668.

Cusack, R., and D. K. Cone. 1986. Studies on Gyrodactylus salmonis (Yin and Sproston, 1948) parasitizing fry of Salvelinus fontinalis (Mitchill). J. Wildl. Dis., 22: 209-213.

Darwin, C. 1871. The Descent of Man, and Selection in Relation to Sex. John Murray, London.

Davies, A. J. S., J. G. Hall, G. A. T. Targett, and M. Murray. 1980. The biological significance of the immune response with special reference to parasites and cancer. J. Parasitol., 66: 705-721. 
Dawkins, R., and J. R. Krebs. 1979. Arms races between and within species. Proc. R. Soc. Lond. B Biol. Sci., 205: 489-511.

Dick, T. A. 1983. Species and interspecific variation. In W. C. Campbell (ed.), Trichinella and Trichinosis, pp. 31-73. Plenum Press, New York.

Dick, T. A., D. A. Dougherty, and D. L. Wassom. 1988. Trichinella spiralis infections of inbred mice: genetics of the host response following infection with different Trichinella isolates. J. Parasitol., 74: 665-669.

Dobson, A. P. 1988. The population biology of parasite-induced changes in host behavior. Q. Rev. Biol. , 63: 139-165.

Donoghue, M. J. 1989. Phylogenies and the analysis of evolutionary sequences, with examples from seed plants. Evolution, 43: 1137-1156.

Edwards, J. C., and C. J. Barnard. 1987. The effects of Trichinella infection on intersexual interactions between mice. Anim. Behav. , 35: 533-540.

Ehrlich, P. R., and P. H. Raven. 1964. Butterflies and plants: a study in coevolution. Evolution, 18: 586-608.

Embody, G. C. 1924. Notes on the control of $G y$ rodactylus on trout. Trans. Am. Fish. Soc., 54: 48-53.

Endler, J. A., and A. M. Lyles. 1989. Bright ideas about parasites. Trends Ecol. E Evol. , 4: 246-248.

Esch, G. W. 1983. The population and community ecology of cestodes. In C. Arme and P. Pappas (eds.), Biology of the Eucestoda, Vol. 1, pp. 80-137. Academic Press, New York.

Esch, G. W., J. Whitfield Gibbons, and J. E. Bourque. 1975. An analysis of the relationship between stress and parasitism. Am. Midl. Nat., 93: 339-353.

Eshel, I., and E. Aiken. 1983. On the evolutionary instability of inner Nash solutions of the coevolving populations. J. Math. Biol., 18: 123-133.

Eshel, I., and W. D. Hamilton. 1984. Parentoffspring correlation in fitness under fluctuating selection. Proc. R. Soc. Lond. B Biol. Sci. , 222: 1-14.

Evans, W. S., M. Novak, and A. Basilevsky. 1985. Effects of environmental temperature, sex, and infection with Hymenolepis microstoma on the liver and bile duct weights of mice. J. Parasitol., 71: 106-109.

Ewald, P. W. 1983. Host-parasite relations, vectors, and the evolution of disease severity. Annu. Rev. Ecol. Syst., 14: 465-485.

Fallis, A. M., and S. S. Desser. 1977. On species of Leucocytozoon, Haemoproteus, and Hepatocystis. In J. P. Kreier (ed.), Parasitic Protozoa, Vol. 3, pp. 239-266. Academic Press, New York.

Fallis, A. M., S. S. Desser, and R. A. Kahn. 1974. On species Leucocytozoon. Adv. Parasitol., 12: 1-67.

Farris, J. S. 1970. Methods for computing Wagner trees. Syst. Zool., 19: 83-92.

Feeny, P. 1976. Plant apparency and chemical de- fense. In J. W. Wallace and R. L. Mansell (eds.), Biochemical Interaction between Plants and Insects, Vol. 10, pp. 1-40. Plenum Press, New York.

Felsenstein, J. 1985. Phylogenies and the comparative method. Am. Nat., 125: 1-15.

Fisher, R. 1930. The Genetical Theory of Natural Selection. Clarendon Press, Oxford.

Freeland, W. J. 1976. Pathogens and the evolution of primate sociality. Biotropica, 8: 12-24.

Futuyma, D. J., and M. Slatkin (eds.). 1983. Coevolution. Sinauer Associates, Sunderland.

Gittleman, J. L. 1989. The comparative approach in ethology: aims and limitations. In P. P. G. Bateson and P. H. Klopfer (eds.), Perspectives in Ethology, Vol. 8, pp. 55-83. Plenum, London.

Gittleman, J. L., and M. Kot. 1990. Adaptation: statistics and a null model for estimating phylogenetic effects. Syst. Zool., 39: 227-241.

Gleason, L. N. 1987. Population dynamics of Pomphorhynchus bulbocolli in Gammarus pseudolimnaeus. J. Parasitol., 73: 1099-1101.

Greiner, E. C., G. F. Bennett, E. M. White, and R. F. Coombs. 1975. Distribution of the avian hematozoa of North America. Can. J. Zool. , 53: 1762-1787.

Hamilton, W. D. 1982. Pathogens as causes of genetic diversity in their host populations. In R. M. Anderson and R. M. May (eds.), Population Biology of Infectious Diseases, pp. 269-296. Springer-Verlag, New York.

Hamilton, W. D., and M. Zuk. 1982. Heritable true fitness and bright birds: a role for parasites? Science, 218: 384-387.

$\longrightarrow$, and -1989 . Hamilton and Zuk reply. $\mathrm{Na}$ ture, 341: 289-290.

Harvey, P. H., and L. Partridge. 1982. Bird coloration and parasites - a task for the future? Nature, 300: 480-481.

Holmes, J. C., and W. M. Bethel. 1972. Modification of intermediate host behaviour by parasites. In E. V. Canning and C. A. Wright (eds.), Behavioural Aspects of Parasitic Transmission, pp. 123143. Academic Press, New York.

Jaenike, J. J. 1988. Parasitism and male mating success in Drosophila testacea. Am. Nat., 131: 774-780.

Janovy, J., Jr., and E. L. Hardin. 1988. Diversity of the parasite assemblage of Fundulus zebrinus in the Platte River of Nebraska. J. Parasitol., 74: 207-213.

Jermy, T. 1976. Insect-host plant relationships coevolution or sequential evolution? Symp. Biol. Hung. , 16: 109-113.

- 1984. Evolution of insect/host plant relationships. Am. Nat., 124: 609-630.

Kennedy, C. E. J., J. A. Endler, S. L. Poynton, and H. McMinn. 1987. Parasite load predicts mate choice in guppies. Behav. Ecol. Sociobiol., 21: 291-295. 
Kethley, J. B., and D. E. Johnston. 1975. Resource tracking patterns in bird and mammal ectoparasites. Misc. Publ. Entomol. Soc. Am., 9: 231-236.

Khan, R. A., and E. M. Lee. 1989. Influence of Lernaeocera branchialis (Crustacea: Copepoda) on the growth rate of Atlantic cod, Gadus morhua. J. Parasitol., 75: 449-454.

Kilgore, M. W., G. L. Stewart, and N. J. Smatresk. 1988. Oxygen uptake in mice infected with Trichinella spiralis. J. Parasitol., 74: 721-724.

Kirkpatrick, C. E., and T. B. Smith. 1988. Blood parasites of birds in cameroon. J. Parasitol., 74: 1009-1013.

Kirkpatrick, C. E., and H. B. Suthers. 1988. Epizootiology of blood parasite infections in passerine birds from central New Jersey. Can.J. Zool. , 66: 2374-2382.

Kirkpatrick, M. 1982. Sexual selection and the evolution of female choice. Evolution, 36: 1-12.

-1986. Sexual selection and cycling parasites: a simulation study of Hamilton's hypothesis. $J$. Theor. Biol., 119: 263-271.

Kluge, A. G. 1988. Parsimony in vicariance biogeography: a quantitative method and a Greater Antillean example. Syst. Zool., 37: 315-328.

Knopf, P. M., and R. L. Coghlan. 1989. Maternal transfer of resistance to Schistosoma mansoni. J. Parasitol., 75: 398-404.

Kodric-Brown, A., and J. H. Brown. 1984. Truth in advertising: the kinds of traits favored by sexual selection. Am. Nat., 124: 309-323.

Lanciani, C.A. 1986. Reduced survivorship in Dasyhelea mutabilis (Diptera: Ceratopogonidae) parasitized by the water mite Tyrrellia circularis (Acariformes: Limnesiidae). J. Parasitol., 72: 613-614.

- 1988. Sexual bias in host selection by parasitic mites of the mosquito Anopheles crucians (Diptera: Culcidae). J. Parasitol., 74: 768-773.

Lande, R. 1981. Models of speciation by sexual selection on polygenic traits. Proc. Nat. Acad. Sci. USA, 78: 3721-3725.

Leighton, E. A., K. D. Murrell, and L. C. Gasbarre. 1989. Evidence for genetic control of nematode egg-shedding rates in calves. J. Parasitol., 75: 498-504.

Lester, R. J. G. 1971. The influence of Schistocephalus plerocercoids on the respiration of Gasterosteus and a possible resulting effect on the behavior of the fish. Can. J. Zool., 49: 361-366.

Lincicome, D. R. 1971. The goodness of parasitism: a new hypothesis. In T. C. Cheng (ed.), The Biology of Symbiosis, pp. 139-227. University Park Press, Baltimore.

Loker, E. S., D. F. Cimino, G. A. Stryker, and L. A. Hertel. 1987. The effect of size of M line Biomphalaria glabrata on the course of development of Echinostoma paraensei. J. Parasitol. , 73: 1090-1098.
Loverde, P. T., J. Dewald, and D. J. Minchella. 1985. Further studies of genetic variation in Schistosoma mansoni. J. Parasitol., 71: 732-734.

Marcogliese, D. J., and G. W. Esch. 1989. Alterations in seasonal dynamics of Bothriocephalus acheilognathi in a North Carolina cooling reservoir over a seven-year period. J. Parasitol., 75: 378-382.

Margolis, L., G. W. Esch, J. C. Holmes, A. M. Kuris, and G. A. Schad. 1982. The use of ecological terms in parasitology (report of an ad hoc committee of the American Society of Parasitologists). J. Parasitol., 68: 131-133.

Mayden, R. L. 1988. Biogeography, parsimony, and evolution in North American freshwater fishes. Syst. Zool., 37: 329-355.

Maynard Smith, J. 1978. The Evolution of Sex. Cambridge University Press, Cambridge.

- 1985. Sexual selection, handicaps, and true fitness. J. Theor. Biol., 115: 1-8.

McLennan, D. A., D. R. Brooks, and J. D. McPhail. 1988. The benefits of communication between comparative ethology and phylogenetic systematics: a case study using gasterosteid fishes. Can. J. Zool., 66: 2177-2190.

McLennan, D. A., and J. D. McPhail. 1990. Experimental investigations of the evolutionary significance of sexually dimorphic nuptial colouration in Gasterosteus aculeatus (L.): the relationships between male colour and female behaviour. Can. J. Zool., 68: 482-492.

McPhail, J. D., and S. D. Peacock. 1983. Some effects of the cestode (Schistocephalus solidus) on reproduction in the threespine stickleback (Gasterosteus aculeatus): evolutionary aspects of a hostparasite interaction. Can. J. Zool., 61: 901-905.

Milinski, M. 1984. Parasites determine a predator's optimal feeding strategy. Behav. Ecol. Sociobiol., 15: 35-37.

Milinski, M., and T. C. M. Bakker. 1990. Female sticklebacks use male coloration in mate choice and hence avoid parasitized males. Nature, 344 : 330-333.

Minchella, D. J. 1985. Host life-history variation in response to parasitism. Parasitology, 90: 205-216.

Mitter, C., and D. R. Brooks. 1983. Phylogenetic aspects of coevolution. In D. J. Futuyma and M. Slatkin (eds.), Coevolution, pp. 65-98. Sinauer Associates, Sunderland.

Mode, C. J. 1958. A mathematical model for the co-evolution of obligate parasites and their hosts. Evolution, 12: 158-165.

Moll, H., and G. F. Mitchell. 1988. Analysis of variables associated with promotion of resistance and its abrogation in $\mathrm{T}$ cell-reconstituted nude mice infected with Leishmania major. J. Parasitol., 74: 993-998.

Moore, J., and J. Lasswell. 1986. Altered behavior 
in isopods (Armadillidium vulgare) infected with the nematode Dispharynx nasuta. J. Parasitol., 72: 186-189.

Moore, J., J. Lasswell., M. Freehling, D. Horton, and D. Simberloff. 1987. Host age and sex in relation to intestinal helminths of Bobwhite quail. J. Parasitol., 73: 230-233.

Moore, J., D. Simberloff, and M. Freehling. 1988. Relationships between bobwhite quail socialgroup size and intestinal helminth parasitism. Am. Nat., 131: 22-32.

Mulvey, M., T. M. Goater, G. W. Esch, and A. E. Crews. 1987. Genotype frequency differences in Halipegus occidualis-infected and uninfected Helisoma anceps. J. Parasitol., 73: 757-761.

Munger, J. C., and J. C. Holmes. 1988. Benefits of parasitic infection: a test using a ground squirreltrypanosome system. Can. J. Zool. , 66: 222-227.

Nadler, S. A., and B. M. Honigberg. 1988. Genetic differentiation and biochemical polymorphism among trichomonads. J. Parasitol., 74: 797-804.

Nagy, Z. M., K. J. Porada, and J. A. Anderson. 1983. Under-nutrition by rearing in large litters delays the development of reflexive, locomotor, and memory processes in mice. J. Comp. Physiol. Psychol. , 91: 682-696.

Nur, N., and O. Hasson. 1983. Phenotypic plasticity and the handicap principle.J. Theor. Biol. , 110: 275-298.

O'Donald, P. 1962. The theory of sexual selection. Heredity, 17: 541-552.

- 1967. A general model of sexual and natural selection. Heredity, 22: 499-518.

Paepke, H. J. 1983. Die Stichlinge. A. Ziemsen Verlag, Wittenberg.

Pagel, M. D., and P. H. Harvey. 1988. Recent developments in the analysis of comparative data. Q. Rev. Biol., 63: 413-440.

Pennycuick, L. 1971. Quantitative effects of three species of parasites on a population of threespined sticklebacks, Gasterosteus aculeatus. J. Zool. Lond., 165: 143-162.

Pickering, A. D., and P. Christie. 1980. Sexual differences in the incidence and severity of ectoparasitic infestation of the brown trout, Salmo trutta. J. Fish Biol., 16: 669-683.

Pomiankowski, A. 1987a. Sexual selection: the handicap principle does work-sometimes. Proc. $R$. Soc. Lond. B Biol. Sci., 231: 123-145.

- $1987 \mathrm{~b}$. The costs of choice in sexual selection. J. Theor. Biol., 128: 195-218.

-1989. Choosing parasite-free mates. Nature, 338: $115-116$.

Price, P. W. 1980. Evolutionary Biology of Parasites. Princeton University Press, Princeton.

Prokopic, J., and K. Krivanec. 1975. Helminths of amphibians, their interaction and host-parasite relationships. Acta Sci. Nat. Acad. Sci. Bohemoslov.
Brno., 9: 1-48.

Quinn, S. C., R. J. Brooks, and R. J. Cawthorn. 1987. Effects of the protozoan parasite Sarcocystis rauschorum on open-field behaviour of its intermediate vertebrate host, Dicrostonyx richardsoni. J. Parasitol., 73: 265-271.

Rand, A. S., S. Guerrero, and R. M. Andrews. 1983. The ecological effects of malaria on populations of the lizard Anolis limifrons on Barro Colorado Island, Panama. In A. G. J. Rhodin and K. Miyata (eds.), Advances in Herpetology and Evolutionary Biology, pp. 455-471. Museum of Comparative Zoology, Cambridge.

Rau, M. E. 1983. Establishment and maintenance of behavioural dominance in male mice infected with Trichinella spiralis. Parasitology, 86: 319-322.

- 1984. Loss of behavioural dominance in male mice infected with Trichinella spiralis. Parasitology, 88: $371-373$.

- 1985. The effects of Trichinella spiralis infection of pregnant mice on the future behavior of their offspring. J. Parasitol., 71: 774-778.

Read, A. F. 1987. Comparative evidence supports the Hamilton and Zuk hypothesis on parasites and sexual selection. Nature, 328: 68-70.

- 1988. Sexual selection and the role of parasites. Trends Ecol. EF Evol., 3: 97-102.

Read, A. F., and P. H. Harvey. 1989a. Reassessment of comparative evidence for Hamilton and Zuk theory on the evolution of secondary sexual characters. Nature, 339: 618-620.

$\longrightarrow$, and $-1989 \mathrm{~b}$. Read and Harvey reply. $\mathrm{Na}$ ture, 340: 105.

Read, A. F., and D. M. Weary. 1990. Sexual selection and the evolution of bird song: a test of the Hamilton-Zuk hypothesis. Behav. Ecol. Sociobiol., 26: 47-56.

Ressel, S., and J. J. Schall. 1989. Parasites and showy males: malarial infection and color variation in fence lizards. Oecologia, 78: 158-164.

Richards, C. S. 1975. Genetic factors in susceptibility of Biomphalaria glabrata for different strains of Schistosoma mansoni. Parasitology, 70: 231-238.

—. 1976. Variations in infectivity for Biomphalaria glabrata in strains of Schistosoma mansoni from the same geographical area. Bull. WHO, 54: 706-707.

Richards, C. S., and P. C. Shade. 1987. The genetic variation of compatibility in Biomphalaria glabrata and Schistosoma mansoni. J. Parasitol. , 73: 1146-1151.

Riggs, M. R., and G. W. Esch. 1987. The suprapopulation dynamics of Bothriocephalus acheilognathi in a North Carolina Reservoir: abundance, dispersion, and prevalence. J. Parasitol. , 73: 877892.

Rollinson, D., and V. R. Southgate. 1985. Schistosome and snail populations: genetic variability and parasite transmission. In D. Rollinson and R. M. Anderson (eds.), Ecology and Genetics of Host- 
Parasite Interactions, pp. 91-109. Academic Press, London.

Ruse, M. 1979. The Darwinian Revolution. The University of Chicago Press, Chicago.

Schall, J. J., and M. D. Dearing. 1987. Malarial parasitism and male competition for mates in the western fence lizard, Sceloporus occidentalis. Oecologia, 73: 389-392.

Schall, J. J., and G. A. Sarni. 1987. Malarial parasitism and the behavior of the lizard, Sceloporus occidentalis. Copeia, 1987: 84-93.

Schall, J. J., A. F. Bennett, and R. W. Putnam. 1982. Lizards infected with malaria: physiological and behavioral consequences. Science, 217: 1057-1059.

Schmidt, G. D., and L. S. Roberts. 1985. Foundations of Parasitology. 3rd ed. Times Mirror/Mosby College Publishing, St. Louis.

Scott, D. K., and T. H. Glutton-Brock. 1989. Mating systems, parasites and plumage dimorphism in waterfowl. Behav. Ecol. Sociobiol., 26: 261-273.

Scott, M. E., and H. C. Gibbs. 1986. Long-term population dynamics of pinworms (Syphacia $o b$ velata and Aspiculuris tetraptera) in mice. J. Parasitol., 72: 652-662.

Sitepu, P., C. Dobson, and P. J. Brindley. 1986. Nematospiroides dubius: multiple infections in mice bred for immune responsiveness. J. Parasitol., 72: 559-564.

Smith, R. A., M. L. Kennedy, and W. E. Wilhelm. 1985. Helminth parasites of the raccoon (Procyon lotor) from Tennessee and Kentucky.J. Parasitol., 71: 599-603.

Stock, T. M., and J. C. Holmes. 1987. Dioecocestus asper(Cestoda: Dioecocestidae): an interference competitor in an enteric helminth community. J. Parasitol., 73: 1116-1123.

Swofford, D. L., and W. P. Maddison. 1987. Reconstructing ancestral character states under Wagner parsimony. Math. Biosci., 87: 199-229.

Tanuri, A., P. P. de Andrade, and D. F. de Almeida. 1985. Trypanosoma cruzi: isolation of cloned strains and characterization of their infectivity. $J$. Parasitol., 71: 397-402.

Taylor, G., and G. Williams. 1982. The lek paradox not resolved. Theor. Popul. Biol., 22: 392-404.

Tomlinson, I. P. M. 1988. Major-gene models of sexual selection under cyclical natural selection. Evolution, 42: 814-816.

Trivers, R. L. 1972. Parental investment and sexual selection. In B. Campbell (ed.), Sexual Selection and the Descent of Man, 1871-1971, pp. 136-179. Aldine, Chicago.

Wakelin, D. 1978. Genetic control of susceptibility and resistance to parasite infection. Adv. Parasitol., 16: 219-308.
Wallace, B. M., and D. B. Pence. 1986. Population dynamics of the helminth community from migrating blue-winged teal: loss of helminths without replacement on the wintering grounds. Can. J. Zool., 64: 1765-1773.

Ward, P. I. 1988. Sexual dichromatism and parasitism in British and Irish freshwater fish. Anim. Behav., 36: 1210-1215.

Wassom, D. L., T. A. Dick, N. Arnason, D. Strickland, and A. W. Grundmann. 1986. Host genetics: a key factor in regulating the distribution of parasites in natural host populations. $J$. Parasitol., 72: 334-337.

Whitlock, S. C. 1937. An apparent case of sexual difference in resistance to parasite infections. $J$. Parasitol., 23: 426.

Wiley, E. O. 1988a. Vicariance biogeography. Annu. Rev. Ecol. Syst., 19: 513-542.

- 1988b. Parsimony analysis and vicariance biogeography. Syst. Zool., 37: 271-290.

Wright, C. A. 1971. Flukes and Snails. Allen \& Unwin, London.

Wright, K. A., E. Weidman, and H. Hong. 1987. The distribution of cells killed by Trichinella spiralis in the mucosal epithelium of two strains of mice. J. Parasitol., 73: 935-939.

Yanez, D. M., and A. G. Canaris. 1988. Metazoan parasite community composition and structure of migrating Wilson's phalarope, Steganopus tricolor Viellot, 1819 (Aves), from El Paso County, Texas. J. Parasitol., 74: 754-762.

Zahavi, A. 1975. Mate selection - a selection for a handicap. J. Theor. Biol., 53: 205-214.

- 1977. The cost of honesty. J. Theor. Biol., 67: 603-605.

Zohar, A. S., and M. E. Rau. 1986. The role of muscle larvae of Trichinella spiralis in the behavioral alterations of the mouse host. J. Parasitol., 72: 464-466.

Zuk, M. 1984. A charming resistance to parasites. Nat. Hist., 93: 28-34.

1987a. Variability in attractiveness of male field crickets (Orthoptera: Gryllidae) to females. Anim. Behav. , 35: 1240-1248.

- 1987b. The effects of gregarine parasites, body size, and time of day on spermatophore production and sexual selection in field crickets. Behav. Ecol. Sociobiol., 21: 65-72.

- 1988. Parasite load, body size, and age of wildcaught male field crickets (Orthoptera: Gryllidae): effects on sexual selection. Evolution, 42: 969-976.

- 1989 . Validity of sexual selection in birds. $\mathrm{Na}$ ture, 340: 104-105. 